\title{
Lessons from the "BPO journey" in a public housing company: toward a strategy for BPO
}

\author{
Marie-Therese Christiansson \\ Department of Information Systems, \\ Karlstad Business School, Karlstad University, Karlstad, Sweden, and \\ Olof Rentzhog \\ Vinna Matchen AB, Östersund, Sweden
}

\section{Lessons from the "BPO journey"}

Received 22 April 2017 Revised 23 December 2017 29 August 2018 27 January 2019 Accepted 1 March 2019

\begin{abstract}
Purpose - Despite many efforts within organizations toward business process orientation (BPO), research on real-world experiences remains in its infancy. The purpose of this paper is to redress the existing knowledge gap by analyzing a Swedish public housing company that has made notable effects regarding BPO and to explore lessons learned from the BPO journey (from 1998 to 2013).

Design/methodology/approach - The point of departure is principles in the BPO foundation, principles of successful BPM and effects in empirically based literature. The reconstruction of the narrative case study describes milestones and critical junctions, as well as effects based on quantitative and qualitative data.

Findings - Effects in BPO are demonstrated in terms of higher customer satisfaction, increased innovative ability, improved operational performance, higher employee satisfaction and, as a result of these, increased profitability. Theoretical constructs with implications for the theory building on BPO are suggested in a three-layer management framework - with capabilities and abilities emerging from the case study used as an illustrative example.

Practical implications - Lessons are learned regarding critical practices related to advancement in BPO. A strategy-building process based on eight design propositions is suggested to define the pre-conditions for $\mathrm{BPO}$ in an organization.

Originality/value - This is the first longitudinal case study to provide a comprehensive view and detailed insights of a BPO journey and top management performance toward a business process-oriented organization. Practitioners and BPM community get valuable insights into how the temporality and the context shape the $\mathrm{BPO}$ maturity process in terms of new organizational structure and roles during the journey.
\end{abstract}

Keywords Capabilities, Business process management, Longitudinal case study,

Business process orientation, Effects, Strategy for BPO

Paper type Case study

\section{Introduction}

Business process management (BPM) as a process lifecycle management approach has well-known benefits that include increased customer satisfaction, greater efficiency and cost savings, more transparency of activities and business agility (Van Looy, 2014; vom Brocke et al., 2014). There is growing awareness that organizations require an integrated and holistic lifecycle approach - that is, a management based on operations in cross-functional end-to-end business processes (BPs) with a structure, culture and mindset by employees toward an external customer value - in order to achieve the intended effects of business process orientation (BPO) (Christiansson and Van Looy, 2017; Movahedi et al., 2016; Tregear, 2016; Harmon, 2015; Van Looy et al., 2014). Previous research shows that higher BPO maturity is associated with higher business performance (McCormack and Johnson, 2001;

(C) Marie-Therese Christiansson and Olof Rentzhog. Published by Emerald Publishing Limited. This article is published under the Creative Commons Attribution (CC BY 4.0) licence. Anyone may reproduce, distribute, translate and create derivative works of this article (for both commercial \& non-commercial purposes), subject to full attribution to the original publication and authors. The full terms of this licence may be seen at http://creativecommons.org/licences/by/4.0/legalcode

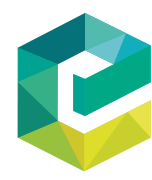

Business Process Management Journal pp. $373-404$ Emerald Publishing Limited $1463-7154$ DOI 10.1108/BPMJ-04-2017-0091 
BPMJ

26,2

Tarhan et al., 2015); accordingly, we know that attention to better management of BPs results in better operational performance (Movahedi et al., 2016). BPM requires capabilities in governance, methods, information technology (IT), culture, people and strategic alignment (Rosemann and vom Brocke, 2015) in actions ranging from business process modeling and measurements to innovations and business transformations to implement new/better ways of working. The strategic alignment is the work to align the organizational strategy and goals with the strategy for BPO and intended effects. Nevertheless, BPM has focused more on the modeling practice of BPs than on the employees contributing to initiatives (Kohlbacher and Gruenwald, 2011) and on those performing the BPM. Vom Brocke and Mendling (2017) stated that there are few available real-world cases that provide practical experiences from BPM projects. The same situation applies for practical experiences from organizations that are business process oriented. Hence, research on practitioners' abilities to organize, manage, and act toward a strategy for BPO and intended effects has so far been neglected. A strategy toward BPO should incorporate the answers to the research question:

$R Q 1$. "What managerial actions facilitate organizational capabilities and employees" abilities toward BPO?

Work practices toward BPO will promote a process-oriented authority (Movahedi et al., 2016) with roles, knowledge, abilities and responsibilities needed for the BPM.

In this paper, BPO maturity reflects the organizational level, from the defined, linked, and integrated stage to the extended stage of BPs, using the five attributes that constitute the prerequisites for increasing maturity (Lockamy III and McCormack, 2004): view, structure, jobs, measures and beliefs. Business performance and the esprit de corps increase according to the degree of the attributes and the movement from an internal focus (within functions) to an inter-functional focus and then to an inter-organizational focus (Lockamy III and McCormack, 2004). Movahedi et al. (2016) stressed that organizations with goals of achieving financial and operational benefits should focus on the intra-organizational level. If the organizational goal is centered on achieving higher customer satisfaction, the need is a better management of BPs at the intra-organizational level (indirect effect) as well as the inter-organizational level (direct effect). Previous research has stated that there is little empirical evidence of BPO effects in general (McCormack, 2001; Kohlbacher, 2010; Tarhan et al., 2015) and hardly any from a holistic organization perspective in particular (only parts of the organization or a single project). Reported effects in the literature are primarily related to the organizational benefits of a process-oriented approach (Kohlbacher, 2010; Tarhan et al., 2015; Dijkman et al., 2016; Movahedi et al., 2016) or of increased quality and improvements in BP performance (Dijkman et al., 2016; Tarhan et al., 2015; Kohlbacher and Reijers, 2013; Raschke and Ingraham, 2010; Kohlbacher, 2010), whereas reporting on effects for employees (McCormack and Johnson, 2001; Kohlbacher, 2010; Zaheer et al., 2010) is rare. In addition, studies on capabilities from a BPM maturity view (Rosemann and vom Brocke, 2015) and a BP maturity view (Van Looy et al., 2014) can be found. However, capabilities from a BPO maturity view will motivate our study and, as far as we understand, this is the first longitudinal case study providing detailed insights into a BPO journey toward a business process-oriented organization. Thus, the present study is justified. The aim is to reconstruct the BPO journey in a Swedish company, which will add a case in a Scandinavian context to the field, broaden the scope to $\mathrm{BPO}$ and contribute to future comparisons.

The case, Karlstads Bostads AB (KBAB), is a municipally owned housing company with approximately 7,400 apartments and altogether the company has about 140 employees working under the motto "creating life quality homes for Karlstad residents" (KBAB, 2019). The empirical data were collected by revisiting the BPO journey in an illustrative case, from the BPO initiative starting from 1998 to 2013 when the company had implemented BPO on a large scale. The journey is defined as major milestones in time and routing of critical junctions, highlighting people's actions, responsibilities and abilities. 
The remainder of the paper is structured as follows. We begin with an operationalization of the foundations in the BPO construct and reported effects in the literature (Section 2), followed by a description of the research design (Section 3). The major milestones in the BPO journey are then described, followed by an analysis of their effects (Section 4). Next, in the case study analysis, we take a practical perspective in terms of organizational capabilities and employees abilities to formulate normative lessons on managerial actions toward a strategy for BPO (Section 5). Finally, theoretical and practical implications, including a discussion of research limitations and suggestions for further studies, end the case study (Section 6).

\section{Foundations of business process orientation}

In order to understand the directions for the BPM work practice, the principles in the BPO foundation and reported effects from empirical studies are explained below.

BPO can be seen as an organization that places special emphasis on outcomes and customer satisfaction based on a process view, thinking and acting in processes (McCormack and Johnson, 2001). Holistic and integrated lifecycle approach is suggested, that is, management based on the alignment of strategy and operations in end-to-end BPs with a culture and mindset by employees toward customer value and continuous improvements (Christiansson and Van Looy, 2017; Van Looy et al., 2014). A business-process-oriented organization is referred to as a horizontal organization (Rummler and Brache, 1995), which means that it works in and improves flows of information and activities to support resource management across departments as well as between inter-organizational partners and stakeholders, to take the advantage of significant potential. Thus, people performing in BPs and people managing an organization based on its processes need to know which BPs exist within the organization (defined and described) and how these are related to one another within and between organizations. The implications for people are that those who gain insights into their own role and actions in the overall business performance (end-to-end processes) can act better (Steneskog, 1991). The horizontal organization often requires teams of people (Willaert and Van den Bergh, 2007) to run the business, as well as a new leadership approach with a coaching and cooperative leadership style (Hammer, 2007a). Furthermore, in a business process-oriented organization, the top management needs to support the core idea and initiatives (Hammer, 2007a) in order to achieve intended effects. To implement and manage BPs, the organization needs coaches instead of bosses in order to motivate and engage people performance. Hammer and Stanton (1999) stated that the existence of process owners (such as being responsible for the end-to-end $\mathrm{BP}$ and its improvements) is the most visible difference between a BPO organization (process enterprise) and a traditional organization. Another visible difference is the main process map, that is, a BP architecture picture as opposed to a traditional organization chart (Rummler and Brache, 1995; Tregear, 2014). BPs are analyzed and designed based on process descriptions (BP maps) as the leading artefact that cannot be detailing every part of the $\mathrm{BP}$ or expected results in a comprehensive documentation (Rosemann, 2006; Thiemich and Puhlmann, 2013). Hence, enable transparency and follow the phase of changes between business, process and system to succeed (Österle, 1995) as well as aligning the management level to the operational (Thiemich and Puhlmann, 2013).

One main message in the process literature concerns developing the BPs that are related to and contribute to the business goal with a defined purpose in order to be relevant (Keen, 1997). Instead of treating processes as unconnected islands, an organization also depends on how its BPs interact and are managed (Kohlbacher, 2010; Tregear, 2014). Thus, in order for an organization to adopt the process view of its organization and to perform in a business process-oriented way, a process structure is needed as guidance and basis for further improvements (Tregear, 2014). Hence, a defined management, core and supporting/enabling processes from the highest levels of a process structure hierarchy (architecture), represents everything that the organizations do and why. The value propositions are embedded in the 
BPMJ

26,2

highest-level processes derived from the organization strategy. Thus, an organization strategic intent, defined in visions, missions and values are executed via its BPs where their employees, partners, customers and systems operationalize the strategy. Decisions are based on facts from the people who know and perform the business (Davenport, 1993).

In addition, IT can act as an enabler for BP improvements (Davenport, 1993) in redesigned processes (Hammer, 1990), as well as an enabler for the BPO per se (Kirchmer, 2017). IT that seamlessly integrates information flowing through a company supports the process approach. Standardized and integrated IT infrastructure can reduce throughput times and failure frequencies of processes (Kohlbacher, 2010). In addition, BPM suites might offer the opportunity for employees to drive process efficiency with automated processes (business process applications) to simplify the employees' workflows. With low-code and business process-based modeling, business applications/IT solutions can be built using drag-and-drop tools and intuitive forms, without requiring the skills of a developer. Besides knowledge and skills in IT and BPM methods, social and communicative skills are the key characteristics of successful BPM professionals (Bergener et al., 2012). BPM covers aspects ranging from process characteristics to the organizational structure required for processoriented work, as well as people working with a customer-focused mind-set (Van Looy et al., 2014). However, there are levels of customer-orientation (Gazzoli et al., 2013) in order to be able to achieve customer satisfaction. The authors' study showed that the employee level of customer-orientation (need to pamper the customer, read the customer's needs, personal relationship and required service delivery) was significantly related to internal quality (efficiency), which, in turn, positively affects customer satisfaction.

In sum, the BPO foundation can be defined in seven principles $(\mathrm{P})$ that specify the requirements for a business process-oriented organization:

- BPO_P1: process view: "Doing the right things" - effectively in horizontal end-to-end BPs, according to defined needs, assignments or possibilities (Rummler and Brache, 1995), with a significant value in the final result for external customers/stakeholders and deliverables for internal customers (McCormack and Johnson, 2001; Rosemann and de Bruin, 2005; Rohloff, 2009; Movahedi et al., 2016).

- BPO_P2: efficiency: "Doing things in the right way"- efficiency in resource management and use of IT as an enabler/innovation in cross-organization flows (Davenport, 1993; Kohlbacher, 2010; Dumas et al., 2013).

- BPO_P3: customers view: knowing the customer expectations to fulfill and exceed in performance (McCormack and Johnson, 2001; Gazzoli et al., 2013).

- BPO_P4: facts from business performance: making decisions based on facts from people who know and perform business and utilizing employee's potentials and performance (Steneskog, 1991; Rosemann, 2006).

- BPO_P5: organization: adapting an organizational structure of BPs (Tregear, 2014) teams and defined roles with a coaching leadership (Hammer and Stanton, 1999; McCormack and Johnson, 2001; Hammer, 2007a).

- BPO_P6: result driven: aligning the organizational visions, strategies, goals and intended effects with BP performance (Österle, 1995).

- BPO_P7: change driven: improving and re-engineering/innovating business performance (Davenport, 1993) with a balance (Rosemann, 2014) of continuously and re-engineering (Hammer and Champy, 1993) efforts.

Van Looy (2014) described BPO as the broader scope including BPM and performance in the BPs. In order to manage performance, with performance measurement based on processes rather than functions, alignment and common focus across separate organizational units 
can be achieved (Hammer, 2007b). In addition, the people performance in BPs needs to be empowered with values and beliefs, as well as be motivated and engaged in the continuous improvements from a customer point of view (McCormack, 2001). In order to be able to change and innovate, measures can be drivers (Tregear, 2014; McCormack, 2001) as well as define roles where employees are granted authority and delegated responsibilities to take their own decisions for their actions in the direction of customer value (Movahedi et al., 2016). The BPM work practice (dotted circle) aligns management and operational performance, i.e. mediating the $\mathrm{BPO}$ principles to business performance (the completed arrow), as well as motivate and engage people to partake in $\mathrm{BP}$ improvements and governing (the dashed arrow) when working toward BPO (thin arrow). Therefore, we define the BPM work practice in terms of different areas of organizational capabilities and people abilities, see Figure 1.

\subsection{BPM performance}

Figure 1 distinctly shows the mediating function of the BPM work practice. BPM is an important piece of a strategy toward BPO (Skrinjar and Trkman, 2013). vom Brocke et al. (2014) presented ten principles specifying the requirements for a good BPM:

- BPM_P1: context awareness - BPM performance should consider factors that distinguish contexts between organizations, such as size, strategy, industry and market, as well as context within organizations, such as objectives of BPM and available resources (employees, IT systems, etc.). Thus, BPM should be adapted to suit the existing circumstances in which it is applied. It should fit the management practices in the organization (external and internal factors, goals, corporate culture, etc.) and the management of BPs according to the process type (management/core/ support) and the process nature (degree of automation, standardization, repetitiveness, etc.) The latter is constructed according to vom Brocke et al. (2016). Furthermore, the context awareness is also important in maturity evaluations, in that what and how to measure is not a one-size-fits-all approach; adjustments on scope, levels and measures are crucial in tailoring the assessment model (Christiansson and Van Looy, 2017).

- BPM_P2: continuity - BPM performance should be a permanent practice that facilitates continuous gains in efficiency and effectiveness. Thus, BPM should be
Lessons from the "BPO journey"

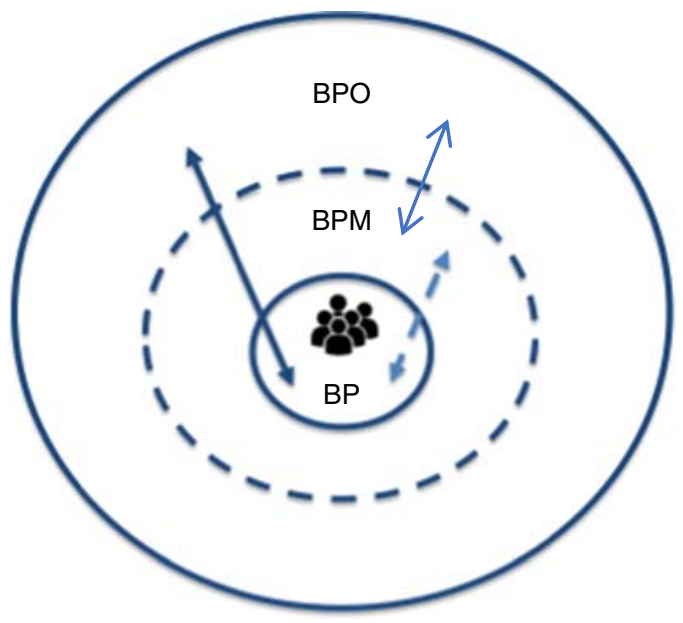

Figure 1 .

$\mathrm{BPO}$ with the "people factor view" 
BPMJ

26,2

378

establishing a long-term approach with defined roles with responsibility to be able to leverage the potential of a systematic work to achieve the intended effects of BPO. While research has found that BPM only leads to sustained competitive advantage if BPs are continuously improved (Trkman, 2010), the literature also emphasizes the benefits of radical redesign of organizations (Hammer and Champy, 1993). However, BPM goes beyond these single interventions; ambidextrous organizations, which have both an exploitative and explorative performance at the same time, demand different competencies (Rosemann, 2014). Hence, BPM work practice can be conducted in a one-off change project, continuous business improvements, redesign/ innovation initiative and in an ambidextrous mixture. In order to achieve continuity, a BP mindset and actions according to the $\mathrm{BPO}$ principles will become a natural part of the daily work, that is, building a culture which is supportive of BPM (Schmiedel et al., 2013). The internalization of these values can be stimulated by adapting communication, leadership behaviors, reward structures and governance practices (vom Brocke et al., 2014). In addition to increased responsibility and influence on the business performance, a rewarding/incentive system (Willaert and Van den Bergh, 2007) might be used to motivate performance and initiatives.

- BPM_P3: enablement - BPM performance should invest in the own capabilities of an organization and abilities of employees rather than a narrow and short-term focus on BPM software tools and external consultants. Research shows that BPM competencies in staffing of key BPM positions/roles are crucial in actively developing a long-term BPM capability (Müller et al., 2016). Companies have to concentrate on their competencies in order to create strategic competitive advantages (Eicker et al., 2008; Oberweis, 2010) with organizational-related roles as well as business process-related roles. Thus, the HR recruitment process plays a significant role and should handle the management's intended effects in BPO and BPM objectives. In addition, people involved in BPM need knowledge about the foundations in BPO (zur Muehlen, 2008), methods to increase readiness to change and change management techniques (Hammer, 2007a), as well as the ability to communicate, coordinate and integrate different BP improvements initiative/projects within the organization (Harmon, 2015), hence, BPM-related roles.

- BPM_P4: holism - BPM performance should take a holistic approach that comprises the whole organization and enterprise environment, including strategic, methodological, technical and social/cultural aspects (Hammer, 2007a; Willaert and Van den Bergh, 2007; Trkman, 2010; vom Brocke et al., 2014), rather than an isolated focus on specific areas of an organization or specific aspects in BPM. In a BPO organization, the financial and HR systems are related to the resource management based on process needs (Hammer, 2007a).

- BPM_P5: institutionalization - BPM should be integrated in the organization work to reach a horizontal, customer-focused process of thinking and acting. One way of doing this is by establishing formal BPM roles and responsibilities. Hammer and Stanton (1999) stated that the existence of process owners (who are, for example, responsible for the end-to-end $\mathrm{BP}$ and its improvements) is the most visible difference between a BPO organization (process enterprise) and a traditional organization. An organizational factor that seems to reflect on BPM maturity in organizations is the existence of a specialized group/department that is recognized as the process specialists. Some organizations begin with a BPM Center of Excellence working as an internal consulting group that provides support to process modeling, analysis, design and project expertise, along with standard tools, methods and techniques. A more mature or experienced organization is expected to have a process management 
governance group, that is, a BPM Office that oversees the organization portfolio of processes, and aligns, prioritizes and authorizes transformation efforts. However, the BPM Office's portfolio of service offerings may vary widely (Rosemann, 2010; Willaert and Van den Bergh, 2007). Recent research shows that some organizations appoint a chief process officer (CPO) within the top management team, that is, assigning BPM accountability to senior executives (Kratzer et al., 2018). Findings show that CPOs are generalists and possess a unique skill set to serve as change agents, who facilitate process-oriented strategy and execution, driving cultural change throughout the organization as integrators and influencers across managerial ranks and corporate functions.

- BPM_P6: involvement - BPM should involve all affected stakeholder groups: "The active involvement of employees fosters a true sense of ownership and even increases organizational performance" (vom Brocke et al., 2014, p. 10). Thus, the responsiveness of employees and their commitment are critical for the outcome. However, the authors did not clarify what employee participation really means in practice, apart from representing them in BP modeling and redesign workshops. Nevertheless, their suggestions for achieving involvement are through mechanisms such as interactive feedback sessions, idea boxes and collaborative process modeling.

- BPM_P7: joint understanding - BPM should view, define and analyze the organization by using a common (process) language. Ideally, processes are part of conversations among different stakeholders reflecting a shared understanding of processes and ways in which their improvement can be sought. Process models (diagrams), storyboards and cartoons are examples of the language that organizations want to speak to communicate about their processes (vom Brocke et al., 2014).

- BPM_P8: purpose - BPM should align with the strategic mission and goals of the organization in order to change and create value. vom Brocke et al. (2014) stressed the fact that although the principle is obvious, it is often forgotten in practice. One issue in the BPM work practice is creating transparency about the business and the organizational system. In addition, the top management needs to communicate their strategic purposes - such as efficiency gains, networking, sustainability, gender equality, working environment and agility - in order to get the prerequisites for alignment.

- BPM_P9: simplicity - BPM should invest resources (such as effort, time and money) in relation to its purpose (vom Brocke et al., 2014).

- BPM_P10: technology appropriation - BPM should make opportune use of technology, particularly IT, as driver of value creation (Davenport, 1993). Countless IT solutions can be used to foster the efficiency and effectiveness of BPs. The selection, adoption and exploitation of IT should be inherent in BPM and managed from the point of view of supporting the enterprise, rather than single departments or individuals (vom Brocke et al., 2014, p. 13).

In sum, the BPM principles should implement the BPO principles in maturity stages toward intended effects in business process-oriented organizations and BP performance.

\subsection{Effects on $B P O$}

The benefits associated with $\mathrm{BPO}$ in the literature review conducted by Movahedi et al. (2016) were categorized into three major constructs: financial, operational and customer satisfaction. In the present study, we use a fourth construct - employee satisfaction - to define effects in BPO. Empirical data on effects presented in the literature have been re-categorized to some extent and structured based on the four constructs; see Table I. 
BPMJ

26,2

\section{0}

Employee satisfaction

Customer satisfaction

Financial results

Operational performance

Table I.

Effects and measures in literature reported on empirical cases
Measures in empirical cases

Increased customer satisfaction, higher levels of quality/improved product quality, efficiency in process outcomes, reduction of failures/customer complaints, increased delivery ability (market on time) and delivery reliability (delivery time), productivity (increase of sales), improved performance quality (process/product/service), reduced time/increased speed (throughput time/lead time), faster decision making on-site (Skrinjar et al., 2008; Kohlbacher, 2010; Raschke and Ingraham, 2010; Kohlbacher and Reijers, 2013); Dijkman et al., 2016; Tarhan et al., 2015)

More positive corporate climate, less internal conflict, commitment, mutual trust, improved collaboration/cooperation, work organization, relationships with suppliers, improved transparency (responsibility/information), trust in leadership, new leadership style (coaching) and alignment of objectives, prepared to go extra mile (McCormack and Johnson, 2001; Skrinjar et al., 2008; Kohlbacher, 2010). Increased employee satisfaction, innovativeness, the customer is well-known, customer integration, improved staff morale, learning, "esprit de corps" and performance, new employees can faster/better adjust to the new job (Skrinjar et al., 2008; Kohlbacher, 2010; Zaheer et al., 2010; Tang et al., 2013; Dijkman et al., 2016)

Increased company value, market responsiveness, market share and competitiveness, profitability, cost reduction, lower (inventory) costs, increase of earnings/sales/profits, equity ratio, net profit margin and operating profit, new employments (Skrinjar et al., 2008; Kohlbacher, 2010; Tarhan et al., 2015)

Improved overall business performance, interdepartmental connectedness, control, communication and flexibility, greater connectedness, reduced inter-functional/ departmental conflicts and realization progress/project success, standardization and integration of IT architecture and reduction on inventory/required space for production, increased operational complexity, duplication of functional expertise (McCormack and Johnson, 2001; Skrinjar et al., 2008; Kohlbacher, 2010; Kohlbacher and Reijers, 2013; Dijkman et al, 2016)

Based on Table I, we can state that positive effects of BPO are clearly more often reported than negative effects, which are even lacking in the reporting according to Kohlbacher (2010). However, this has been questioned on the assumptions that there is an imbalance between the purpose of research and organizations' unwillingness to share their failures (Kohlbacher, 2010; Tarhan et al., 2015). Moreover, the effects and measures in Table I do not show evidence of relations, that is, causal effects. In addition, we need to consider that these studies are based on different definitions of BPO (not always the holistic view of structure and culture included), different research design, different sectors, different environments and situations faced in the organization (initiative and context, such as needs, constraints, incidents and objectives).

Results from the study conducted by Skrinjar et al. (2008) show that BPO leads to better non-financial performance and indirectly to better financial performance. Tarhan et al. (2015) reported positive effects, but findings from one case indicate that even if the BPM has an influence, neither a process view nor cross-functional integration has a significant effect on innovation performance. In addition, findings from another case show that process success does not necessarily result in business success. Some relations are empirically proven, for example, the fact that BPM results in high customer satisfaction and high product quality (according to external assessments) and significantly contributes to an increase of sales and productivity (Kohlbacher, 2010). Movahedi et al. (2016) suggested that higher levels of BPO at intra-organizational level provide direct financial and operational benefits for organizations, and higher levels of $\mathrm{BPO}$ at the inter-organizational level provide direct customer satisfaction benefits as well as indirect financial and operational benefits. In addition, organizations have better financial performance (especially across processes), delivery and delivery ability (Kohlbacher, 2010; Kohlbacher and Gruenwald, 2011). 
Furthermore, high-quality BPs deliver high-quality products and services (Kohlbacher, 2010) and have a significant impact on employees and their performance (Zaheer et al., 2010). The monitoring of processes and the application of methods for continuous process improvement has a significant and positive relationship with the performance of organization (Kohlbacher and Reijers, 2013). In addition, studies in other domains might support the effects reported in the BPO literature, such as Bakotic (2016), who stated that job satisfaction (cf. employee satisfaction) determines organizational performance, rather than the other way around (organizational performance determining job satisfaction). Dijkman et al. (2016) showed that innovative organizations appear to develop BPM capabilities, suggesting that innovativeness leads to higher maturity and better business performance, provided that there are processes in place to enable organizations to cash in on their innovativeness. Even if BPM's emphasis is on continuous improvements, automation and standardization, empirical evidence shows a higher innovativeness. On the contrary, Tang et al. (2013) stated that there is no direct link between BPO and innovation and that a process view is not sufficient to enhance organizational innovation performance. Niehaves et al. (2014) suggested that BPM as a dynamic capability should be developed to fit the organizational environment internal and external contingencies. Thus, different effects and lack of general knowledge on relations between effects shows that different degrees of BPO maturity are needed in organizations. In addition, the strategy on BPO and intended effect need to be aligned with the strategy in organizations (Palmberg, 2010; Niehaves et al., 2014), i.e. there is no one-size-fits-all approach.

In sum, BPO maturity can be defined as the understanding of the BPO principles that are used in roles that handle BPM principles in order to generate intended effects in BPO (purpose) and degree of BPO maturity.

\section{Research design}

A possible reason for the lack of studies of BPO journeys is the difficulty of knowing when and who would regard a company as a BPO, "a trip" that might take 10-15 years, and a defined maturity depending on when and who you ask in the organization. In our case, the $\mathrm{BPO}$ journey started at KBAB in 1998 and is described until 2013. However, it is difficult to know when the journey really started and with what - a thought, an idea - and by whom. The end of the journey is even more difficult to identify because KBAB is still on the "never-ending journey" of continuous improvements with innovative solutions and new business models. In 2015, the BPO journey officially ended as a part of the long-term leadership of a CEO leaving the company; consequently, we decided that 2013, with effects in 2014, was appropriate to summarize the lessons learned.

In addition, Harmon (2015, p. 123) argued that, despite its widespread adoption and impressive results, BPM is still in its infancy. "Even companies that have implemented it are far from finished and many companies - indeed many industries - have yet really to begin." Hence, it might be difficult to get access to information from companies. It is a challenge to conduct a longitudinal study and be able to gain access to people who "joined the whole trip" in order to reconstruct the BPO implementation and analyze the effects. It requires access to people who worked in the same company during the organizational transformation, as well as a structured, reflective and continuously evaluated journey to analyze impacts on business performance and financial results. The purpose of the present study is to analyze one BPO organization in depth in order to explore the effects of BPO. Therefore, we conducted a case study (Yin, 2014) to learn from one situational context in a company and their abilities to work toward BPO. Our case study was qualitative and interpretive (cf. Walsham, 2006) and classified as retrospective with a reflective learning on effects in relation to $\mathrm{BPO}$ foundations.

The present study follows a practice research approach (Goldkuhl, 2011) with a situational inquiry (what practitioners say they do and what they actually do) based on the
Lessons from the "BPO journey" 
BPMJ

26,2

knowledge domain of $\mathrm{BPO}$ as a common interest shared by researchers and practitioners. We drew on work practice to investigate the phenomena of strategy making. The study can be described as a process research (Langley, 1999) to explain how BPO has evolved over time and why. Hence, we identify critical junctions from a beginning to an end-state and explain the business results evolution through analyses of major milestones connecting the two points in time, seeking to explain the effects of BPO.

\subsection{Data collection and analysis}

$\mathrm{KBAB}$ is a municipal housing company founded in 1942. In addition to managing the properties in all respects, the public housing company is involved in tasks of social responsibility, for example, ensuring more security and less segregation in the community, as well as reducing energy consumption in buildings for a more sustainable construction and property sector. KBAB is included in a Municipal Group through Karlstad City Hall AB. In addition, there is a supportive central organization called SABO (the Swedish Association of Municipal Housing Companies) that has approximately 300 affiliated member companies.

Until 2016, KBAB's vision and mission included keywords like "a home for you," "find and keep the right customers," "offering price worthy rental apartments with added value and satisfying meaningful everyday needs," "in conjunction with the customers and value-creating partners." In addition, the business idea states that KBAB's efforts would contribute to the long-term attraction and profile of Karlstad municipality. Furthermore, a number of structured conversations were held between September 2015 and June 2016 with a business developer at KBAB with insights in the strategic intensions to capture the story of the BPO journey. The story was partly documented in vision and mission statements, strategic reflections, plans and results of the quality assurance efforts in the "Host 2000" program, document on KBAB's responsibilities in society and a guest lecture at Karlstad Business School in 2016 on KBAB's journey and results over time. In addition, a report on the company culture and business performance (Beiron and Olin, 2010) was used together with bachelor thesis based on KBAB (Grudin, 2015; Shirani, 2016). The latter are studies on motivation in $\mathrm{BPM}$ and strategic/operational effects of BPO. The present study had the necessary access to a strategic coordinator/business developer who has been involved in the plans from the start and implementation during the whole organizational transformation toward BPO. To avoid bias, when working close to one practitioner for a long period of time, we used a diversity of data sources in our in-depth reconstruction. Moreover, empirical data from 19 recorded interviews with the management, employees, partners and customers (i.e. tenants) in 2010 on KBAB's approach were used (BeBo, 2017) as well as three cases on customer experiences.

Research studies from 2010 to 2016 with empirical results (e.g. Kohlbacher, 2010; Kohlbacher and Reijers, 2013) or surveys of empirical studies (e.g. Dijkman et al., 2016; Tarhan et al., 2015) were used as secondary data. The overall intention is to identify all different kinds of effects, based on empirical studies. Hence, we have not given any consideration to the research methods used in the other studies to be found in the literature on different areas $(\mathrm{BPO} / \mathrm{BPM} / \mathrm{BP})$ or relationships to organizational maturity or their use of maturity models. In addition, we have not considered which or how many companies/organizations are included in related studies and from which countries and industries. The methodology applied for selecting literature does have certain limitations, as relevant publications, not indexed by the databases used for our search in this study were excluded.

In our analysis, we "identify and make analytical generalizations to the general case of which [our] study is an instance" (Langley et al., 2013, p. 8). In other words, we theorize data to not only identify meaning in principles and roles but also to provide insights of critical junctions (why) and major milestones (what) that appear to be crucial, beside the facts and figures on effects. 
When analyzing the data, we followed the main steps of the process research methodology (Langley, 1999). First, we identified a sequence of major milestones during a 15-year period that answered the questions of what happened and when. The narrative are following the stages in BPO maturity by Lockamy III and McCormack (2004). Second, we developed a layer and plotted results from measures in relation to the time line for the BPO journey to provide BPO effects in a number of illustrations (Figures 2-6). Third, we sought to answer why it happened by discussing critical junctions as insights/decisions made with a major impact on core capabilities to advance BPO. Finally, the analysis in Section 5 follows the stages and attributes in BPO maturity listed by Lockamy III and McCormack (2004) that constitute the prerequisites for increasing BPO maturity and enablers to move from one process stage to the next one. Criteria from the European Foundation for Quality Management (EFQM, 2019) are used to explain the advancement from one stage to the next. We assume (cf. similar criteria in the ISO 9000 certification) that enablers such as people, leadership, strategy and planning, partnership and resources and processes can explain the advancement of BPO in organizations. Thus, results that the organization achieve are the result of enablers. Excellent organizations meet or exceed the expectations of their customer, their employees and other stakeholders in the extended stage according to Lockamy III and McCormack (2004). According to the authors, the extended stage (a holistic mindset, governed BPs, working in team, roles with authority and influence, measures as drivers, direct customer and employee satisfaction, indirect financial and operational effects), the integrated stage (a holistic understanding, implemented BPs, an integrated structure/inter-organization, roles

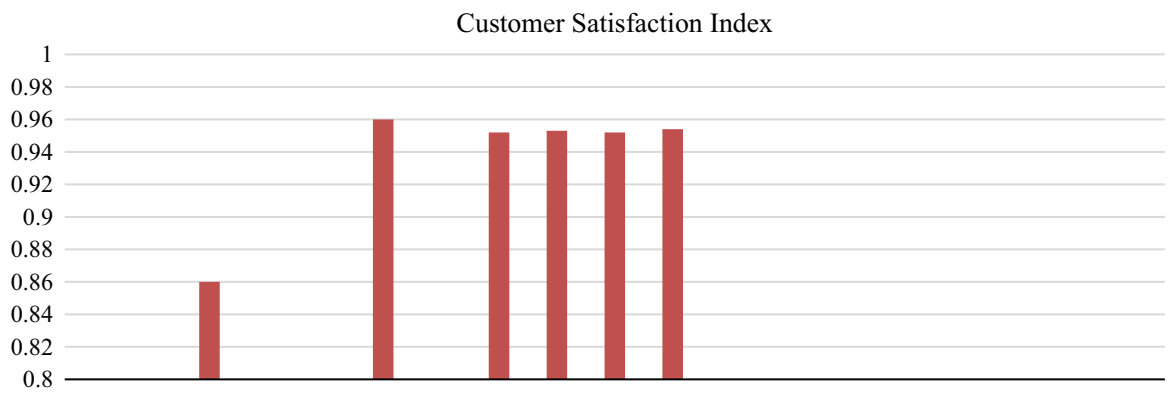

1994199519961997199819992000200120022003200420052006200720082009201020112012

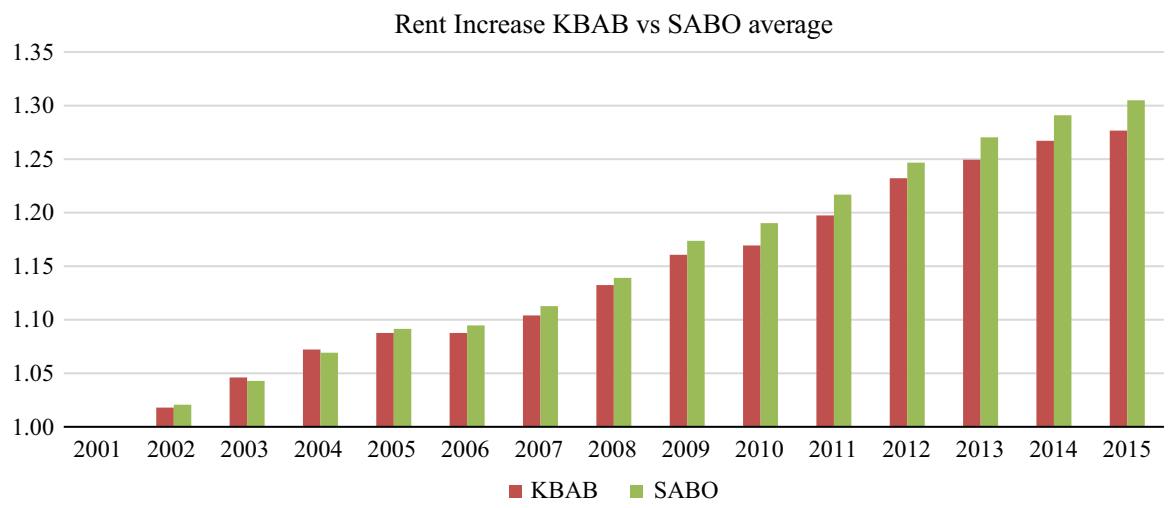

Lessons from the "BPO journey"

383

Figure 2. Customer Satisfaction Index in $\mathrm{KBAB}$
Figure 3.

The level of increased rent rate in $\mathrm{KBAB}$ compared to the industry average (SABO) 
BPMJ

26,2

384

Figure 4.

The level of energy consumption in $\mathrm{KBAB}$ compared to the industry average (SABO)

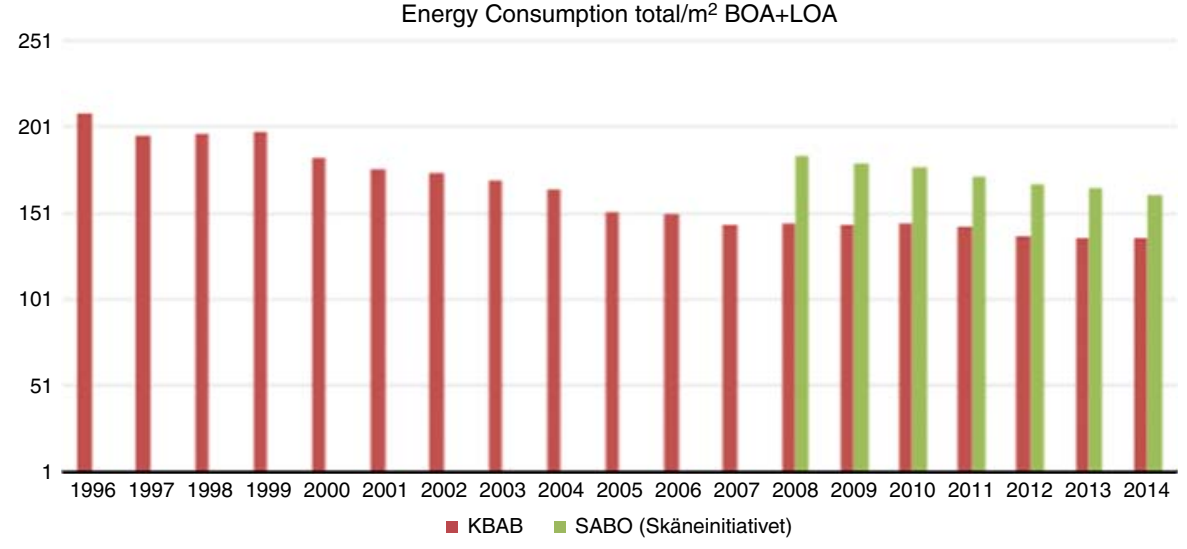

Sick Leave KBAB vs National Average
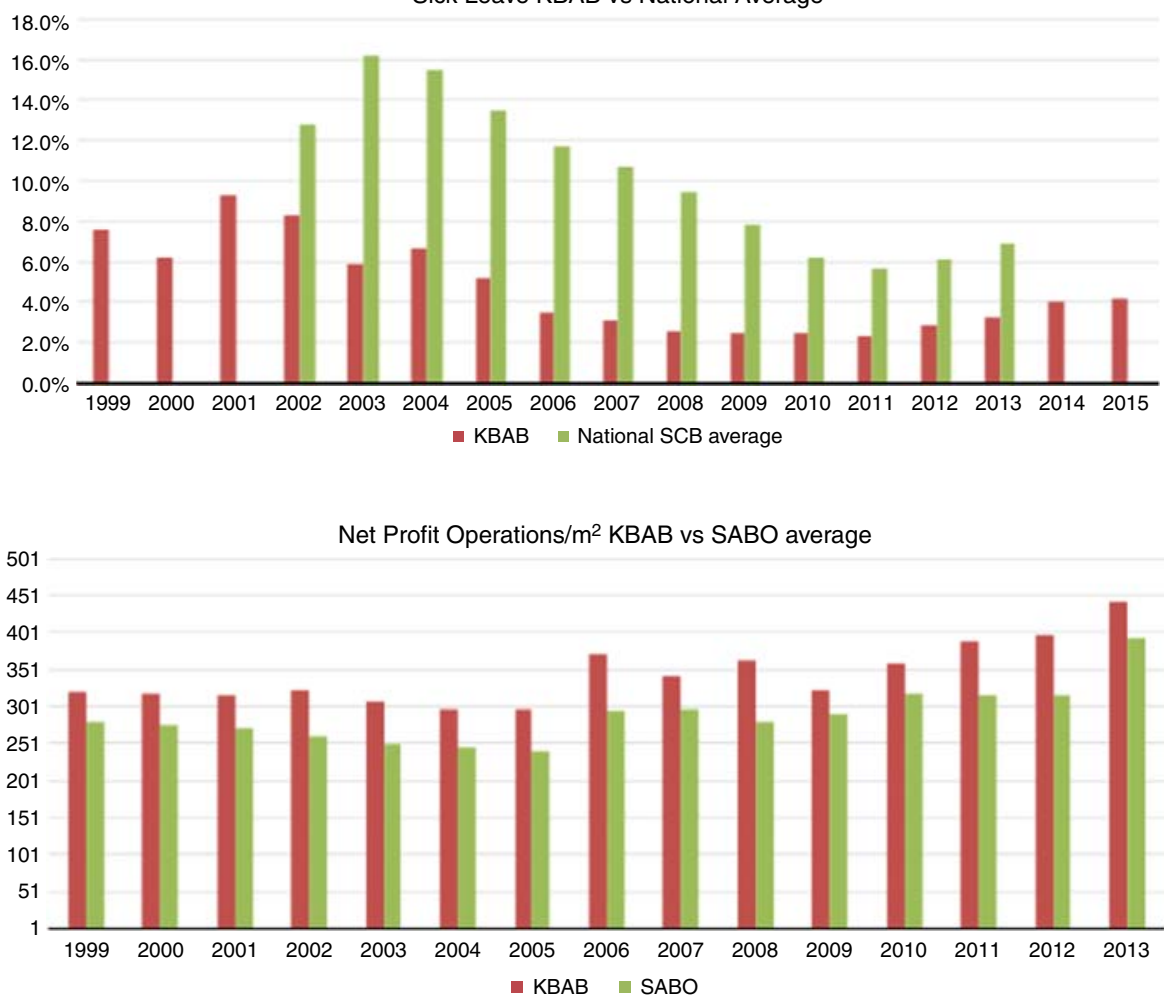

Figure 6.

The net profitability operations $/ \mathrm{m}^{2}$ in KBAB compared to the industry average (SABO)
Figure 5.

The level of sick leave in $\mathrm{KBAB}$ compared to the national average (SCB)

with accountability, ownership for measures, direct customer satisfaction, indirect financial and operational effects), the linked stage (customer focus, use of BP documentation, evaluated and improved BPs, collaboration, roles with responsibility, linked measures, direct financial and operational effects), as well as the defined stage (stating a customer focus, defined and mapped BPs, ad hoc roles with responsibility, defined measures, 
direct financial and operational effects) will advance the maturity from the $a d$ hoc stage when business performance is unpredictable, ill-defined, measures are not in place, and jobs and organizational structures are based on functions. In addition, cooperation and customer satisfaction is low and costs are high.

\section{The BPO journey}

The point of departure of the BPO journey is the fact that the rent level was high and the government subsidies were gradually phased out and a new CEO arrived (in 1994) with a result-driven business mindset. In the following sections, major milestones will guide the "story telling." Major milestones (M\#) are defined as important actions that have a major impact on the business model, performance and effects.

\subsection{The defined stage (1998-)}

$B P O$ principles. The need for a balanced budget set the objectives, a purpose toward financial effects, employee satisfaction, and operational performance (M1). The management idea was to perform business in a more efficient way without functional barriers. Customers appreciated the janitors, who had a high sense of service working close to the customers and were highly rated in the customer satisfaction evaluations. Despite this, there was a need for increased authority for employees and improvements (M1).

$B P M$ principles. A course in cross-boundary flow orientation (M3) inspired a few management-level people with responsibility for results. The journey was a management initiative and the involvement can be characterized as a communication strategy, where "why" and results was communicated in workshops rather than modeling sessions (M3). In 1999, the Host 2000 Program had a new business plan, vision, mission and profiling strategy implemented through own business developer of an organization rather than a project with external project managers (M2). Hence, the company has been able to maintain and develop the organization as maturity increased instead of falling back after the end of the project. A number of workshops were conducted in order to educate and prepare employees in crossboundary thinking to understand and engage in the change of the organization structure (M3). The management identified, described, and defined business in processes/flows (M3). Three core processes were established: "finding the customer," "taking care of the customer" and "caring for the real estate" (land and houses). The heat, water, and electricity consumption (M4) were measured (M3) in all buildings and supported by a software tool to analyze the consumption, as statistics were an important part of the decision basis for resource allocation.

Roles. Strategic and operational issues were divided (M4) as new teams and roles were established (M5) and all employees had to apply for their new roles. Tenant service management teams (M5) with an extended customer responsibility were introduced in residential areas. Employees had a defined mandate, responsibility and ability and the best people to plan and take decisions regarding their own work were identified. The tenant service manager teams were fairly autonomous regarding customer responsibility in terms of inspections and managing disturbance complaints, which were examples of new business areas and responsibilities. However, not everyone was happy in their new role, lacking qualifications or the personality required to handle all the different types of tasks. Thus, a new comfort role (M5) was introduced, which was based on individual capacities. The idea was that every employee should work with tasks that they were good at, felt committed to or wished to try to increase their personal development. The operational responsibility was placed at the team level and the team itself had to choose who was best suited for various tasks to ensure that the whole operation was managed optimally. In each team, there was a rotating coordinator role (M5) and a coordinating team (M5) handled the personal resources. Thus, the objective was to increase job satisfaction and emphasize personal development as a 
BPMJ

26,2

personal commitment to gain better business performance. The process owners (M5) worked in manager teams (M5) and had a comprehensive view of the processes and an overall picture of the development efforts. They were responsible for the continual improvements and for supporting the tenant service manager teams along with the comfort role holder, who identified customer needs, suggested solutions, were motivated to simplify and improve business performance, and were responsible for carrying out the work. Ideas were handled directly by the tenant service manager teams and process owners. Thus, the process moved quickly from idea to decision to implementation, followed by testing and monitoring of the improvement process to find simpler and smarter ways to work. Managers were assigned the role of strategic coordinators (M5) and were made responsible for the HR flows of personnel, recruiting, salary setting and for ensuring that process owners and tenant service manager teams operated smoothly through motivational conversations.

\subsection{The linked stage (1999-)}

$B P O$ principles. Values in the company were defined (M3) to unite the organization and establish the principles of work, namely trust, closeness, sensitivity, creative innovation and comfort. An optional flat maintenance was introduced (M6). The concept was meant to lower the basic rent, letting the tenant decide on any redecoration and floorboard replacement and then pay the cost in the form of installments for a five-year period. The concept was called +Service (additional choice), that is, the customer had the choice of service in addition to the basic level, which meant a lower rent increase than other housing companies.

BPM principles. Employees defined "flow areas" for process owners and comfort role staff to discuss in order to reach participation and consensus in information, problems and improvements (M3). The idea was to work on suggestions from employees and take advantage of persons acting as drivers. In addition, mentor networks were introduced (M3) to offer opportunities for employees to choose one person they trusted to be a mentor for "talks in walks." Thus, in an informal way, during walks reflect on their works situation and ideas for improvements.

Roles. The role of the tenant service manager (M5) was established, which involved working closely with customers and mastering many different skills and abilities for handling a variety of tasks based on customer needs. Interest groups were introduced in order to increase the amount of different competences. The roles of network coordinator and integration host (M5) were introduced. The network coordinator was incharge of the abovementioned activities and of the contact with the associations for sponsorship if they organized activities for KBAB's tenants. This replaced the collaboration with the tenants' association, which received grants for leisure activities with less customer value. For some time, integration hosts were working in residential areas to educate immigrants in language and culture to improve communication between tenants and landlords.

\subsection{The integrated stage (2000-)}

$B P O$ principles. In 2002, the management realized that there would be a growing population of elderly people that the society could not afford to take care of (M6) Thus, the concept of Safe Living was developed in residential areas with many elderly people, where both the landlord and the municipal home care services were represented and worked together. In 2003, a new way of working with partnering in inter-organizational collaboration (M7) started under the slogan of "those who contribute belong." A strategic partnering for renovation and construction was managed in 2004, which provided the ability to maintain the same organization in more projects, thus leading to continuous improvements (M7). With every new project, the quality level was increased, impacting the business. A framework agreement was signed for the large-scale development of smart homes with 
individual metering and billing of water and electricity consumption. Increasing responsibility was taken for social security with activities for the customers and +Safe Living. The company drove the initiative for a wind farm (M6) in Lake Vänern and a new rental policy was introduced and a property valuation was made. The low-energy house "Seglet" (M6) was built with KBAB-designed insulated walls and low load on the environment and energy. In 2007, a business environment analysis (M9) was conducted in order to look forward and identify what is important in the near future of business operations and offerings. Food waste sorting (M4) was introduced in a few neighborhoods. In 2010, the building of the residential area "Sjögången land" started, aiming for an LEED Gold Certification. The construction of the apartments was based on high-technology innovation (M6). In addition, a parking lot was transformed into a park in the millionprogram housing area "Hemvägen," inspired by an exhibition on how a residential area can be changed with art to the benefit of people's experience and the status of the residential area (M6). The decision was made that KBAB should take over the Student Housing Company with 520 company-owned apartments and access to 1,000 externally owned apartments (M10). The law on public housing from 2011 stipulates that a public good should be based on commercial principles (M10).

$B P M$ principles. In 2000 , the quality program was integrated in the new organization structure according to the core BPs (M2). The organization was reviewed and the core processes "finding the customer" and "taking care of the customer" merged into "the customer flow" (M3). Focus groups were used for customer dialogue in five residential areas and all employees participated in cross-corporate environmental training (M3). Inspiration days were conducted for all employees and KBAB leisure started, giving employees a chance to try new interests. It was an employee initiative where interested people met and suggested activities for employees at a small cost with the intention of strengthening the KBAB spirit. Personality values were defined as being caring, positive, flexible and responsible (M3). A BPMN suit was implemented and detailed process descriptions for automated BP applications were developed based on aims to simplify employees' ways of working (M3). Energy declarations were implemented in 2008 (M3) and the company was certified as an energy group itself and carried out an in-house energy certification. BPs were mapped, resulting in a classification structure for information/documents, to the delight of archive management and decision makers (M3).

Roles. The role of care manager (M5) involved ensuring that suitable residential areas with good accessibility were chosen and supplied with stairwell cleaning, activities, cafes, etc., to reduce the need for future healthcare. In addition, the strategic coordination team ceased and the coordinators instead became a part of their respective team (M5). The role of business developer (M5) was introduced.

\subsection{The extended stage (2012-)}

$B P O$ principles. The flow-driven management groups were responsible for one area each and people with knowledge of the business, together with a coordinator, were involved in managing the strategic planning and the projects that could not be handled by teams and process owners because of their complexity. In 2012, building modules were used in production under a new concept called "Home of Friends" (M6), designed for two students sharing an apartment. Floating homes were constructed to deal with future floods in attractive waterside locations and a plan was drawn up for a radon-safe accommodation for all apartments $\left(200 \mathrm{~Bq} / \mathrm{m}^{3}\right)$ in $2020(\mathrm{M} 4)$.

$B P M$ principles. The strategies, project priorities and self-assessment were handled in the management teams (M5) Thus, the strategic action plan was based on and connected to 14 management teams, which were managed by eight to ten key employees who were
Lessons from the "BPO journey"

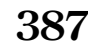


BPMJ

26,2

responsible for getting the overall picture of the sub-processes and making comprehensive and wise decisions (M3). The concept of "lubricating talks" was coined as essential for the efficiency of the organization. When responsibility is divided among several people, there is an opportunity to go through the business in more depth (what and why). When it is necessary to cover more aspects, several management teams were involved in the case handling. The idea was that more people close to the business could contribute and share the responsibility for the management in the company. Consequently, information on how decisions were made was not required to the same degree because so many people were involved. In order to align values and business areas and deliverables, the control matrix was reworked and linked to the strategic plan for Karlstad municipality, that is, the overarching group-level plan (M3). In addition, the basic team staffing was reviewed (M3) and a workshop with the process owners and coordinators was conducted on the issue of what the organization required of leaders to work in an effective and efficient way (M5). Energy declarations were completed (M4) for all properties with 600 suggestions for improvement (M3). A review of the archives and diary management was also conducted (M3). All engagements in the company were placed in the classification structure. Processes were named at the "header level" of process descriptions compiled into a list and made visible.

Roles. Intotal, 14 flow-driven management groups (M5) were introduced in 2012, according to defined core- and sub-processes. The process owners managed the budget for sub-processes (M9).

\subsection{Effects in a company toward a business process-oriented organization}

Reported effects in the literature (Section 2) indicate that business process-oriented organizations are in a position to expect customer satisfaction, improved operational performance, increased profitability (Movahedi et al., 2016) and employee satisfaction (McCormack and Johnson, 2001; Kohlbacher, 2010).

In our discussion and analysis of effects, we have chosen the measures that are suitable for measuring our sample of effects, possible to compare with the industry average (SABO), available for the period of time, and available on the same scale for the whole period.

Customer satisfaction. The CEO at KBAB stated that satisfied customers who remain tenants provide a stable neighborhood where people enjoy living and feel that they get value for their money. Customer satisfaction is an investment because it increases the attractiveness and status in the residential area, thus raising the property value, and makes it possible to keep up the rent levels, which allows room for continuous development. Sweden's nation-level measurement system of customer satisfaction - the Swedish Customer Satisfaction Barometer (SCSB) - is a uniform, cross-company, cross-industry measurement instrument of customer satisfaction and evaluations of quality of products and services. The original SCSB model (Fornell, 1992) contains two primary antecedents of satisfaction: perceptions of a customer's recent performance experience with a product or service and customer expectations regarding that performance. The Customer Satisfaction Index (CSI) is an indicator of customer experience where tenants have the opportunity to give their opinions on how satisfied they were with $\mathrm{KBAB}$ as their renter. Customer satisfaction surveys were conducted on four occasions with comparable measures and scale during the period (see Figure 2).

Figure 2 shows that the survey in 1996 (as a baseline before the BPO journey) had a rate of 86 percent satisfied customers. Measurements in 1999 show a significantly increased rate of satisfied customers ( 96 percent), which might be explained by the efforts made regarding responsibility for results, the role of the tenant service manager and the cross-boundary flow orientation from the customer's point of view, as well as the introduction of the optional flat 
maintenance, all of which relate directly to benefits for the customers. Additional examples are staff cleaning the stairwell as part of the concept of Safe Living acting as a catalyst to create venues and activities for older people. Employees working closely with each other and with customers might explain the early increase in result. Other actions, such as defined business in processes with customer responsibilities and decisions made directly by the tenant service manager teams, might provide other explanations why the stable level of customer satisfaction was approximately 95 percent for 2001-2004. Unfortunately, there is no relevant industry comparison on this measure, but the change itself clearly indicates that the performed business development had a significant impact on customer satisfaction. In addition, KBAB's CSI rankings included first place in 1999, sixth place in 2001, fourth place in 2002 and second place in 2003, compared with 30 similar housing companies. Moreover, a measure in 2013, on another scale at another company ranked KBAB 6th out of 65 companies, which indicates that the positive impact on customer satisfaction was sustained over time. In addition, the company noticed that its own customer surveys did not yield any new knowledge in relation to the cost of time spending on conducting them, as tenant service managers and process owners worked so closely with the customers.

An example of an important customer value is the level of the rent. Rent in itself can be difficult to compare between different apartments. However, if we look at the increase in rent, an interesting comparison can be made with the industry average. A successful BPO ought to result in lower rents, at least in our case study. Figure 3 shows the average of the rent development of a tenant in $\mathrm{KBAB}$ compared to the industry average (SABO).

Figure 3 shows that a $\mathrm{KBAB}$ apartment has had an average increase in rent of 28 percent for the period compared to the corresponding percentage for the industry average of 35 percent, according to SABO. The company competes with the private real estate companies and municipally owned companies are not allowed any competitive advantages. The rents are regulated through negotiations with a tenant association. KBAB's accumulated increase was 25 percent in the period 2001-2015, compared with 28 percent for the SABO-related companies. A SEK 30 rent decrease in 2000 also meant that the increase was based on a lower level, which benefited the customer. This is a significant economic value for the tenant and the rent is a central indicator of customer value and also a good indicator of increased efficiency.

This result is even more impressive if we take into account the fact that KBAB had a significant higher rate of renovation of its apartments from the million-program period than the industry average (which usually entails large rent increases in other housing companies). Renovations have been carried out since the early 1990s in a proactive way that is unique in SABO, where 97 percent of the apartments in the million-program are restored. In addition, the Safe Living and the +Accommodations programs increased the service level in many residential areas as well as salaries without affecting the rent so much during the period (the Safe Living program increased by SEK 25/apartment per month). The relatively low level of rent increase would not have been possible unless the company was also costefficient, usually through energy savings in renovation solutions.

A challenge that the business developer mentioned is the impaired customer focus of the supplier, "forgetting" what it is that creates the most value and most positive impact for customers. Possible reasons for this are that a joint inter-organizational business development is lacking and/or that the partner's culture is not as customer focused. Finally, when employees are satisfied with their work performance and feel that "everything is running smoothly," the customer focus can sometimes be forgotten.

Operational performance and innovations. The KBAB employees suggested a number of improvements on a daily basis. Unfortunately, there are no records on how many of them were transformed from idea to action. However, the story above demonstrates KBAB's

Lessons from the "BPO journey" 
BPMJ

26,2

390

ability to perform BP improvements and adapt to new conditions and requirements in the business environment. In summary, the most noteworthy innovations in KBAB are:

- Outdoor waste recovery stations: 95 percent were in place by 1998 and saved costs.

- Safe Living: the model is of national interest and has now been implemented in several locations as it provides a great deal of value for low cost when the cleaning is done in-house and care activities are organized with staff from the municipality to reduce the need for home care.

- Strategic partnering: A new business model, to purchase "a number of projects in one acquisition," which leads to continuous development and improvements beneficial to the next project and so on.

- Floating homes and the low-energy house: thanks to partners, KBAB could both build 12 floating rental apartments and a low-energy house that attracted attention for their technical solutions for many years.

- The in-house energy certification: a unique model through which KBAB created a self-certified organization to perform energy declarations instead of retaining consultants. In five years, all properties were declared and the work of taking care of the 600 improvement proposals started.

- The garage project: a gigantic underground garage was transformed into a place with ever-increasing art elements and classical music in the background. Numerous activities were organized and influential people visited it.

In 2005, KBAB received the national SABO Environment Energy Hunting award. Water consumption had fallen by 15 percent in the 1,400 apartments that had individual metering, which was extended with each renovation and new construction. The washing charge was introduced 2006 for 1,300 apartments, which resulted in people washing more economically to pay for the washing, which led to environmental gains and a rent reduction of SEK9/ month. The renovation of the residential area "Orrholmen" won the Housing Nordic (NBO) Energy Award. In 2009, SABO took the initiative to challenge the member companies with an interest in energy issues and set the national goal of reducing energy use by 20 percent by 2016 . KBAB was not able to set the same goal because it had already done a great deal (it planned to achieve a 10 percent reduction by 2016). However, in $2013 \mathrm{KBAB}$ received the SABO's award for "Energy Challenger of the Year."

Some of the business improvements and innovations regarding the apartments had a direct impact on benefits for the customers. One example is the washing charge, which led to a reduction in rent. Moreover, $\mathrm{KBAB}$ offers a customer choice on level of renovations and thus the rent. The gradual restoration is one example where KBAB cut the energy consumption in one area by half. The rent is important as a central customer value, but it is also a good indicator of increased efficiency. In addition, an increased degree of BPO means that BPs are implemented. Successful BP improvements should lead to increased efficiency and reduced waste. Figure 4 shows the total energy consumption per square meter of apartments in KBAB compared to the industry average (SABO). The average of the SABO companies with an interest in energy issues (an initiative starting in 2009) shown below is higher for all SABO companies, but statistics are unfortunately lacking.

Figure 4 shows the evolution of the total energy consumption per $\mathrm{m}^{2}$ for KBAB during the period 1996-2014 and a comparison with the industry average (SABO) for the period 2008-2014. It is noteworthy that KBAB not only had a significantly lower consumption (18 percent over the comparative period) than the industry average, but also had a steady improvement trend during the period. 
Employee satisfaction. The work environment survey has shown improvements in all areas since 1997. Employee influence was increased and an incentive pay structure was introduced. A new labor policy and a new payroll system were implemented to support the flat organization. It was considered important to change the structures of working hours and wages to have an impact. The staff adapted their work and services to customer needs and joint meetings were held on values and employee benefits. Employee involvement is a key when making decisions based on facts from people who know and perform business. Hence, BPO should lead to a low level of sick leave. Sick leave is an indicator of how employees feel and their satisfaction at work. Figure 5 shows the level of sick leave in KBAB compared to the national Central Bureau of Statistics average.

As Figure 5 shows, the journey had a very positive development on the level of sick leave, which was cut in half and remained at that level for a long period until 2012, when it increased slightly again. KBAB's rate of sick leave is significantly lower than the industry average, which indicates that the journey toward BPO had a positive effect on employees. This could be explained by management trust, more responsibility allocations, a mandate to make decisions, a high degree of involvement in improvements and a close dialogue in teams and with customers.

Increased profitability. The positive development with an increased degree of BPO in the above areas should also be reflected in the overall profitability of a company. The increased profitability can be seen as an effect of customer and employee satisfaction, operational performance, improvements and innovations. One key indicator measuring this in industry is the net operating income per $\mathrm{m}^{2}$ (see Figure 6).

Figure 6 shows a clear view of KBAB's positive development during the journey when the net operating income increased by 38 percent. The level is significantly above the industry average for the whole period. KBAB has not found any SABO company with a higher yield or higher operating net in relation to total assets. Moreover, KBAB has more employees per apartment than most other housing companies.

\section{Lessons learned from the BPO journey}

An initial reflection is that 15 years is a long time for a journey and would have been difficult to achieve without a foresighted and convincing CEO, a supportive board, and competent and open mined employees and partners. The systematic, long-term and determined character of the step-by-step operational improvements alongside strategic innovations is typical for the whole BPO journey. The lessons learned (L) below show a new organizational structure, several new roles and business models affected during the journey.

The discussion is structured by enablers (EFQM, 2019) and attributes that constitute the prerequires for increasing maturity (Lockamy III and McCormack, 2004) from one stage to the next one. BPO principles, BPM principles and critical practices (Skrinjar and Trkman, $2013)$ in the literature are related to identified milestones (M\#) in the BPO journey. The milestones are characterized as follows: M1: objectives; M2: alignment; M3: foundation; M4: business, societal and operational alignment; M5: roles; M6: innovations; M7: partnering; M8: trends; M9: organization and M10: external factors. Hence, the BPO journey will present findings on how the environmental context (internal as well as external) influences BPM as a dynamic capability (Niehaves et al., 2014).

In the analyses below, we adjusted the use of the integrated stage above by combining it with the linkage stage as we felt no considerable difference to motivate the use of five stages. In addition, comments by the management and employees are used to give some nuances and examples.

\subsection{From the ad hoc stage to the defined stage}

Too often BPM is started without a clear vision of what is needed and why, the lacking link to the strategy in organization is one main reason (Skrinjar and Trkman, 2013), i.e. the 
BPMJ

26,2

purpose for the BPO approach is absent. The need for a balanced budget sets the objectives (BPM_P8) toward financial effects, employee satisfaction and operational performance with a need for increased authority for employees and improvements (M1). A new business plan, vision, mission and profiling strategy were implemented through KBAB's own business developer (M2, BPM_P9). The vision "A home for you - to give, residents a safe and comfortable home in beautiful and well-kept areas" is acknowledged from a customer focus to define the meaning of "doing the right thing" (BPO_P1). In addition, the mission "KBAB shall find and keep the right customers by offering price worthy rental apartments with added value and satisfying meaningful needs, in the city of Karlstad" indicates that the company stresses the importance of knowing the customer (BPO_P3) and the ambition to create added value and fulfill customer needs, as well as "Business shall be marked by prudence and foresight in every business area and pursued in conjunction with the customers and value-creating partners." The latter explains the move toward an environmental and sustainable commitment and the need for shared interest and willingness to contribute (M4). The company has chosen to clearly distinguish between operational and strategic activities and responsibilities (M4) in order to avoid the risk of only engaging in operational activities. The aim was to be farsighted in anticipating problems and to be one step ahead the development in society and the market, which was seen as a wise approach in the face of future demands and conditions. In KBAB, the BPO journey was a top management initiative based on a result-driven mindset (BPO_P6) and a process view (BPO_P1). A course (M3) in cross-boundary flow orientation (BPO_P1, P2) was a point of departure. The management identified, described and defined core processes (M3, BPM_P7), and designed "to-be" BPs to automate (BPO_P2, BPM_P10) rather than to identify improvements in "as-is" business, which were instead "talked through" (BPM_P9). A number of workshops were conducted in order to educate and prepare employees (BPM_P6) in cross-boundary thinking to understand and engage in the change of the organization structure (M3). The involvement (BPM_P6) can be characterized as communicating in workshops on "why" and results rather than conducting joint modeling sessions with employees (M3). Clearly, the top management team not only supported BPM but also was actively involved based on a general consensus (Skrinjar and Trkman, 2013) about a culture building strategy.

New roles were established (BPM_P3) as well as how to cooperate. The tenant service management teams (M5) understood the customer and had the responsibility and mandate to allocate tasks and to make operative decisions (BPO_P3, P4, P5). Thus, those who knew the business and the customers acted directly. Our study confirmed the fact that the empowering of employees to take decisions independently and within teams resulted in smoother operations with shorter throughput times (Skrinjar and Trkman, 2013). In addition, the esprit de corps increases according to the movement from an internal focus (within functions) to an inter-functional focus (Lockamy III and McCormack, 2004). The employee approach in KBAB changed from "my responsibility" to "everyone is helping each other," that is, "everyone's responsibility" in the team. Employees act directly on ideas; the impacts are evaluated and employees work on further improvements if needed. People who lack the ability or the personality required to handle all the different types of tasks were not happy. Therefore, additional roles were established in terms of a comfort role (M5), which was based on individual capacities with responsibility for identifying customer needs and suggesting solutions motivated to simplify and improve business performance and carrying out the work. In addition, everyone relating to the business performance was allowed to make suggestions to all roles and partners, as well as the top management. The approach was to invite (BPM_P6) and evaluate every new idea as soon as possible with a response of immediate action or a put-on-hold. The strategic coordinator stressed the importance of short decision paths to motivate employees to come up with ideas and to see whether things 
happen; knowing that ideas can move quickly makes it more exciting to suggest improvements. Hence, time might be a critical factor. According to the CEO, it is important that people who have ideas feel that they can influence (BPM_P6) and make a difference and that there is freedom of action and a permissive culture regarding mistakes. Perseverance in continuous improvement and innovation efforts, together with the belief that everyone who wants to contribute can act, is the characteristics of the change management philosophy (BPO_P7, BPM_P2). There is an obvious joy in accomplishments among employees based on a close relation to their customers. There was pride in working for the customer and having responsibility for both the customer and the result. The community involvement (M4) was a driving force for people working in public housing and a caring mind was useful to reach customer satisfaction. The idea was that every employee should work with tasks that they were good at, felt committed to or wished to try to increase their personal development. Many different roles were established on different levels to align and coordinate the work practices (BPM_P5) in the organization, manager teams, strategic coordinators, process owners, tenant service management teams, coordinator role and coordinating team (M5).

Skrinjar and Trkman (2013) suggested that a critical practice in BPM is to ensure that employees are regularly informed about performance indicators so they can adjust their behavior in line with the goals ensuring the alignment of process orientation with organizational goals. In KBAB, the goals were communicated in the vision and mission as well as statistics as basis for resource allocation and indicators to ensure effects. However, business process performance results were used to set future improvement targets. Measures important both to internal (M3: consumption statistics) and external use (M4: heat, water and electricity consumption of interest to the customers, the sustainable environment commitment and for winning awards). The strategic coordinator's view was that people want to stay with someone who cares about something that is important to society in the long term, environmentally and socially (M4, BPM_P5). In addition, there is a great deal of power, energy and knowledge among the residents. If they can have a forum to meet, share, and mean something to one another, they will feel better, have a meaningful existence, and begin an upward spiral. The coordinator pointed out that the company has almost no additional costs for the Safe Living accommodation as there is in-house cleaning, which means better managed cleaning and also that customers see more of the staff who can provide more services, which makes it price worthy and increases the value of the properties and being a KBAB resident.

Lessons learned so far:

- Lesson 1 - strategic alignment: vision and mission statement should explicit be linked to the overarching expected outcomes and targets for guidance to customerorientated employees, contributing to the advance of $\mathrm{BPO}$; these are people who facilitate skills to identify needs, interact, co-produce and care for customer value.

- Lesson 2 - leadership: defined responsibility, confidence and trust in teams/roles contribute to the advancement of BPO, a divided focus and time for strategical and operational issues when coaching.

- Lesson 3 - competence: competence in the BPO foundation is crucial to the advancement of BPO. People who understand and act with a horizontal and holistic mindset in business performance and development are identifying and using customers' needs and ideas.

- Lesson 4 - BPM organization: teams, roles and fora need to be established and defined on different management layers in order to get a comprehensive and holistic view of business performance and BPM efforts aligned with goals in the organization. In addition, roles within coordination and communication are a key.

Lessons from the "BPO journey" 
BPMJ

26,2

\subsection{From the defined stage to the linked/integrated stage}

One reflection is that the business plan has been implemented and the strategic choices and actions are reflected in the decisions made. The management works with the business plan integrated with a quality program (M2) and defined values. In addition, the control matrix was linked to the overarching group-level strategic plan (M2) to ensure that their contributions were aligned with the municipal strategy (BPO_P6). Hence, the strategic alignment is advancing to a holistic approach (BPM_P4) that comprises development initiatives in the whole organization and enterprise environment. The last part of the mission, "Our efforts contribute to the long-term attraction and profile of Karlstad municipality," can be viewed as the result of a strategy involving business environment analysis (BPO_P6) in combination with commitment to society (M4) as drivers for innovations and new business models (e.g. +Accommodations). The entrepreneur hotel to develop and retain businesses in Karlstad is one example of community involvement, and another is the +Safe Living approach to support tenants helping each other in a meaningful way with activities and forum. Furthermore, the wind park and the water and electricity consumption measuring are examples of efforts toward a sustainable society (M4).

$\mathrm{KBAB}$ is driving its business development and engagement in a profitable direction on the principles of customer/society needs and "efforts that are doable and feel right" rather than on goal fulfillment. As the strategic coordinator pointed out, not setting goals means that everyone is constantly prepared to reconsider and making changes for improvement. However, the business developer claimed that implementing new ways of working in small steps on the basis of the employees' abilities, trying new tasks, discussing impacts, evaluating and making further improvements or changes are often better approaches than setting goals for the future and deciding when they should be achieved. Thus, continuous follow-up on the daily work (BPM_P9) is more successful in terms of retaining the energy of ideas and not losing it in the administration of goals. However, we believe that affective goals can be effective and efficient without being an administrative burden if used in a more agile way. In addition, some statements in the story telling above can be formulated in terms of goals, such as "reducing energy use" by taking action to lower energy consumption with a measure of $X$ percent. In other words, some goals may be relevant to set indicators. The business developer stated that KBAB's concern is not "when" goals are fulfilled, but "that" values, needs and ideas are fulfilled through measures and dialogue. In addition, we note that KBAB consistently works with measures, values and certifications in improvement and innovation efforts. Unfortunately, however, some measuring has not been using the same scale during the BPO journey.

One purpose of BP modeling is to map the operational work to highlight and clarify work procedures and to visualize a job description when explaining to new employees so they can adjust to the new job better and more quickly (BPM_P7). However, this is not the case when $\mathrm{BPO}$ is implemented in teams choosing their way of working, which is embedded in tacit and shared knowledge in teams that change and continually improve their performance. In $\mathrm{KBAB}$, business operations are continuously evaluated and reviewed in conversations (BPM_P6) between the tenant service manager teams and process owners in "lubricating talks" (Grudin, 2015). This is in line with the critical practices described by Skrinjar and Trkman (2013) in terms of that employees need to understand the end-to-end process and not just their individual activities. However, when working in teams, the focus is on solving problems and performing high-quality services to customers with the best team player at hand. Thus, the conversations with process owners and coordinators are crucial to get the overall picture on how their work impacts others and the strategic alignment needs to be communicated throughout the organization (BPM_P9).

One additional way to communicate and get a joint understanding (BPM_P7) is to perform BP modeling. However, modeling is not regarded as a basis for understanding, 
training or an innovation technique in KBAB. BPs are mapped in order to automate the workflow, to simplify and speed things up. Using a common process language was absent (BPM_P7). Instead, the processes were described and communicated in conversations within the teams and between teams and aligned with management. Hence, the critical practice that employees become acquainted with the process terminology presented by Skrinjar and Trkman (2013) is not confirmed and the process management seemed inspired by an agile approach, only using process description motivated by the purpose to automate processes (BPM_P8; BPM_P9; BPM_P10). We note that KBAB has been mapping processes for three reasons: to define core BPs, then to clarify the information management structure, and finally to automate several internal processes. The third of these has resulted in 27 different BP applications where an automated case handling increases the quality. Thus, KBAB can be described as having "a less modeling-based approach," instead stressing values, conversations, evaluations/ revisions, and decisions based on common gut feelings.

Some potential weaknesses, due to the lack of a visualization of BPs and the use of process descriptions, occurred when employees and management needed to grasp the holistic and horizontal view of the operational business and systems involved (BPM_P4, P8). It might be more effective to map operations and discuss them on the basis of a visualization to make business knowledge more accessible and gain transparency. In addition, it might be difficult to review and design the information management without a description that visualizes the activities conducted and the information in the workflow. Hence, the business operations use, generate, store and publish information that makes an impact on the archive and diary management as well as the information security.

Critical practices stressed by Skrinjar and Trkman (2013) are confirmed in terms of conducting IS development based on BPs (as opposed to functions) by using the BPMN tool for automating and supported internal sub-processes, tasks and errands along with better service provision to the external customers (BPM_P10). In addition, the ability to provide relevant information about business process efficiency to managers is confirmed as IT-systems in KBAB provided possibilities for measuring the energy consumption and support decisions with statistics in business performance. The differences in business context (BPM_P1) show that the document system/information management was highlighted in $\mathrm{KBAB}$, a system with limited impact on $\mathrm{BPO}$ improvement according to the study by Skrinjar and Trkman (2013). In addition, the authors claim that companies should first focus there is/IT support for customer-oriented BPs. The focus should then be on BPM suites that also provide information about business process efficiency. After building this foundation, the focus should be on inter-organizational process integration such as e-business with suppliers.

Target groups of customers (such as the elderly, families and students) were identified and diversified offerings and service levels (such as optional flat maintenance) were carried out (M6). The core process of "Caring for the customer" meant that the tenant service management team worked in close contact with the customer in line with their expressed needs and ideas with effects on the increased service level. Contacts with customers were actively taken to collect suggestions on how to make the area more attractive and to yield more value for the money as committing to the community. In addition, the acting of personal visits and explanations of changes and new business models show that the level of customer-orientation discussed by Gazzoli et al. (2013) - that is, to read the customer's needs, establish a relationship, deliver service and pamper the customer - is important to take into consideration in requirements in order to be able to enjoy and functioning in a business process-oriented organization. It is noteworthy that customer surveys did not yield any new knowledge in relation to the cost of time spent on conducting them, as tenant service managers and process owners worked so closely with the customers. Hence, there was a reduced need to conduct customer evaluations (BPM_P9).

Lessons from the "BPO journey" 
BPMJ

26,2

Partnership. "The right way to do things" (BPO_P2) in KBAB was through strategic partnering and conducting improvements in conjunction with customers, associations and value-creating actors. Like-minded companies that share the same values have been chosen as partners. The movement from an inter-functional focus to an inter-organizational focus (Lockamy III and McCormack, 2004) was a fact. Experiences in KBAB show that interorganizational business development is needed, and partners require a customer-focused culture to be successful.

Lessons learned:

- Lesson 5 - strategic partnership: close relations and collaborative integration with external stakeholders (customers, partners and community) contribute to the advance of $\mathrm{BPO}$, that is, to use an inter-organizational mindset.

- Lesson 6 - monitoring trends: monitoring trends in industry and societal perspectives together with customer behavior are drivers for innovations and data to be used in the advance of BPO.

\subsection{From the linked/integrated stage to the extended stage}

Leadership. The supportive business climate with trust and authorization of employees is an indicator of a coaching leadership. Values are fulfilled through a flat organization where everyone is involved and everyone's knowledge is utilized. The head installation engineer stressed that contact channels are closer and that people in different capacities take an interest in each other's work. As a result, most people think that they are acknowledged and listened to. The strategic coordinator agreed and said that the trick is to give everyone permission to express an opinion and have ideas about anything. The aim is to encourage ideas and suggestions at an early stage and refrain from presenting solutions. The CEO brought up the issue of information as power and the importance of sharing information equally to avoid the hierarchy of some having an information advantage, especially in a flat organization where everyone has equal value and the right to participate.

Commitment is created through the knowledge of business and customers, trust and confidence in ability and opportunity for the individual to influence. In addition, the CEO stressed that issues of roles and ethics are fundamental to KBAB operations. There is a need to stay close when things happen and discuss incidents in the whole company. One service tenant manager explained:

A confident foundation is a prerequisite for any further development. The more we discuss how we work, how we act towards each other, how we want to be perceived, the more united we become and build the same gut feeling. (KBAB, 2010)

Hence, the company realizes that people are a valuable asset, enlarge its potential and help them grow their skills and confidence.

The change management culture was characterized, among other things, by "a good conversation" to solve problems, implement ideas and create unity and a shared understanding, all of which make the work enjoyable (BPM_P5). The BPs and the organization were recurrently revised. Employees implemented new ideas and ways of working in small steps with regular follow-ups (BPO_P7). The basis for improvements was new insights, foresight and ideas generated through conversations, measuring and statistics. Transforming an organization requires a trial-and-error approach and evaluation of new ideas. The regular conversations between employees within teams and customers/ partners and between tenant service managers and the process owner/coordinator (BPM_P6) were crucial in order to implement the daily work and were followed up and decisions were made close to the customer (BPO_P4). 
Strategy and planning. KBAB was organized in a flat organization with one CEO and 14 management teams and budget for the sub-processes (M10). The journey toward BPO involved a number of roles, some with strategic and coordinating responsibility and others with operational responsibility. Hence, our case is not in line with the statement that organizations do not need to replace their traditional structures with process-based ones (Skrinjar and Trkman, 2013), as the hierarchies where erased in the favor of the adaptability and the responsiveness of a process-oriented organization, hence, to remove unnecessary approval levels and to define responsibility for everyone, not only for the management layer. However, KBAB changed roles several times during the journey as well as organization of teams through hierarchal levels several times. It seems that the driver for change in organizational structure was to adapt to possibilities to serve to the customer need and to coordinate between teams as well as align the management and operative level, rather than to furiously attempt to change the organizational structure to become "process organized." Finally, the findings to align the departmental goals with each other and with the core processes (cf. Skrinjar and Trkman, 2013) as a critical practice are not confirmed in our case study. Instead, the defined core processes were in line with the vision and mission statement to set targets that were continuously monitor to measure team effectiveness. As the customers view is explicit, employees working toward the customers' needs perceived that there is such an alignment in the flow-oriented work. Hence, employees both knew and internalized targets into a horizontal, customer-focused thinking and acting in business performance (BPM_P5). The BPM was integrated in the organization from the beginning as it was not defined as a business process change project, instead a strategic top management initiative with a road map and a clear focus to communicate, discuss and experience together with employees. A strategic business developer/coordinator/CPO in the top management team is crucial, assigning BPM principles to senior executives and facilitating the BPO foundation in execution, driving cultural change throughout the organization.

People. KBAB changed the organization, management style and introduced new roles, as well as changed how to cooperate in teams (M5). Two service tenant managers noted that it is an advantage to have been part of the whole transformation and the introduction of "the Bovärd 2000 model," because they "have heard everything that has been said throughout the transformation," which means that they:

[...] know things and are thinking in the right way about many things. New persons do not know the history and the role as a service tenant manager is actually a bit difficult to explain. (KBAB, 2010)

One reflection is that many new roles were introduced during the period, which might be difficult for employees to grasp and handle. Some consequences of the journey, which might be seen as challenges or even negative effects, are noticeable in staff recruitment. It is not easy for new employees to grasp the meaning of the tenant service manager and the situated roles. According to the business developer, it might take a year for a new employee to understand that it is preferable to ask a person who knows the task better than a superior. A negative effect in KBAB caused by this approach is that it impairs the ability to deliver a solution of a more complex issue when a delay is created because people in a team or between teams do not know who should take the responsibility for the issue, that is, who has the expertise (Shirani, 2016). Thus, there is a risk of ambiguity. In addition, trust in the good conversation and openness to contribute and the various sub-processes in relation to the coordinating role have sometimes created ambiguity, especially for the employees who have not taken part from the beginning of the "Host 2000" quality program when the crossfunctional thinking was introduced through instruction and training.

Many new employees who have different and traditional backgrounds sometimes find it difficult to know who is in charge, while others feel that there is a natural and efficient way
Lessons from the "BPO journey" 
BPMJ

26,2

398

of working in tenant service management teams. The same applies to the 14 management teams, in which it is sometimes felt that there are too many members at the cost of a holistic approach. In addition, the expectations on the comfort roles needed to be clarified as the qualification requirements in the tenant service management teams keep increasing year by year:

- Lesson 7 - layered management: holistic management contributes to the advance of BPO - top management performance (vision, mission and strategies for the organization in several management/development areas of an organization) should be aligned with the BPM work practice in order to be able to implement and integrate the strategy and perspectives in the BPs.

- Lesson 8 - external drivers: societal engagement, awards and commitment contributes to the advance of BPO.

In sum, our case study suggests that training in BPO foundations for the management is a prerequisite for advancement in BPO maturity. BPM performance should be a permanent practice integrated as a natural part of the daily work that facilitates continuous gains in efficiency and effectiveness as well as innovations. Thus, BPM should be establishing with defined roles, responsibility and fora to align management and business operations with coordination and conversations. Internal measures, rewarding/incentive systems and external awards might be used to motivate performance and initiatives.

\section{Conclusion}

Hernaus et al. (2016) showed that approximately 75 percent of their surveyed organizations do not approach BPM strategically. Therefore, a strategy-building process, based on eight design propositions, is suggested to define pre-conditions for BPO and support managerial actions toward BPO. In addition, a framework - with capabilities and abilities emerged from the case study used as an illustrative example - is suggested. The three layers of management in BPO is the top management of the organization toward intended BPO effects, the management of the BPM work practice/governing BPs toward a business process-oriented organization and the management of the customer-driven business performance in teams. In addition, the interface between each layer is highlighted to stress the BPM works practice in terms of alignment. See Table II (based on the "people factor view" in Section 2).

BPM should secure a continuous (re-)alignment with the environment (Niehaves et al., 2014). Hence, the layer of management is to be further validated in the theory building on $\mathrm{BPO} / \mathrm{BPM}$ maturity processes. The BPM case initiative by vom Brocke and Mendling (2017) of systematically collecting cases following a unified structure, actions taken, results achieved and the lessons learned is a good way to make the case knowledge easily accessible and transferrable to other contexts. Niehaves et al. (2014) suggested that BPM, as a dynamic capability, should be developed to fit the organizational environment and characteristics together with internal and external contingencies. The present framework is a contribution in that direction with focus on environmental variables and organizational characteristics.

A clear vision and strategy for the organization together with established responsibilities and alignment between layers are considered as a success factor in our case study. The suggested strategy-building process below will assist managers to decide if the pre-conditions in the organization are sufficient for a BPO journey and provide guidance to managerial actions toward a defined degree of BPO. Each phase is separated from each other by gateways, which indicate the outcome when one set of activities has been successfully fulfilled before continuing to the next phase. Phase 1 concerns the prerequisites for $\mathrm{BPO}$, Phase 2 the planning for BPM and Phase 3 the BPM work practice. Although the successive phases must be carried out separately, the activities within each phase will, to some degree, be carried out 
Layer - environment/
characteristics

$\mathrm{BPO}$

Strategic

alignment (L1)

Leadership (L2)

Competence (L3)

Strategic

partnership (L5)

Organization - BPM

alignment

BPM organization (L4)

BPM

Monitoring trends (L6)

BPM - BP alignment Integration

Layered management (L7)

$\mathrm{BP}$

External drivers (L8)

Employee

Financial

results
Effects Capabilities/people's abilities

Customer Culture: knowledge in BPO foundation, foresight, a

satisfaction supportive board, trust in and mandate for employees,

satisfaction

willingness to lead, a coaching/mentoring style, result

awareness, accountability for business processes stated

in the vision document, importance of mindset and training,

business insights and society foresights, strategic and

partnering thinking, innovativeness, value statements

(trust, commitment, responsibility, appraisals, common

value mindset, customer focus, willingness and

responsiveness to change) and stakeholder/environment awareness and responsiveness

Coordination Structure: core- and sub-processes, teams and roles with defined responsibilities in organization and toward BPM

Governance: common approach and terminology, BPM principles and skills in BP analysis/design/implementation/ evaluation/improvement and innovations

Methods: business environment analysis, measuring, statistics, certifications/awards/rewards

IT: business process applications, tasks, and errands along with better service provision to the external customers

Methods: regular conversations, sharing, explaining and listening, training and informing, quality management program

People: competence in business performance, customer

Operational performance
Table II.

Three-layer of management framework for BPO in an organization

in parallel as there are three layers of management involved in the BPO maturity. The assessment of the organizational need, capabilities and abilities are compulsory when defining a BPO strategy. This is in line with the conclusion of Palmberg (2010) that a moderate-toextended process-oriented organizational structure may be preferred after considering the final goals and resources of the organization. Thus, it is not by default that the extended stage of a business process-oriented organization is the target; it might be the defined, linked or integrated stage as the destination of the BPO journey. However, if the organization lack the pre-conditions that would be required and do not have a clear intention of becoming businessprocess-oriented, it is probably waste of time. In order to develop a strategy toward BPO, it is a good idea to increase the possibility of being successful before "the journey" take off. Hence, the suggested strategy-building process is described by eight design propositions (D\#) from lessons learned (L\#) to support managerial actions.

Phase 1 - why BPO?

- D1: define intended effects of BPO and potential drivers (L1, L2, L8).

- Financial, customers/employees' satisfaction and/or operational performance.

- New business models/innovations, commitment to society/community involvement, efforts toward a sustainable society.

- D2: identify development initiatives and perspectives to integrate in business for synergies (L1, L7, L8). 
BPMJ

26,2

400

- Sustainability, digitalization, etc.

The outcome from the first gateway will identify the need for a BPO approach.

Phase 2 - what are the pre-conditions for BPM?

- D3: decide if the top management and the organization qualify for BPO? (L2, L3, L4).

- D4: clarify how the strategic plan is aligned with expected effects and potential drivers (L1, L7).

The outcome from the second gateway will identify the BPO readiness.

Phase 3 - what actions are critical in the BPM work practice?

- D5: establish fora and interfaces between management layers and strategic partners (L2, L3, L4, L5, L7).

- D6: perform a focused and reflective BP modeling, measuring, and revisions. If actions do not yield any new knowledge in relation to the cost of time spending, reduce the effort (L3, L6, L7).

- D7: choose relevant measures, comparable with the industry/societal average available for the period of time and in the same scale (L3, L8).

- D8: share, communicate and learn from improvements (L4).

The outcome from the third gateway is an action plan for BPM.

\subsection{Limitations and further studies}

The main weakness of our case study is that it is limited to one Swedish company with a view to broadening the scope and contributing to future comparisons. In comparison with the BPM case initiative from vom Brocke and Mendling (2017), we suggest further research on comprehensive $\mathrm{BPO}$ journeys to be able to perform comparable studies validating lessons learned across industries as well as international studies. Limitations in the present case study are that we heard a few "voices" from the company studied. First, the "people view" would have been far more representative if we had had the opportunity to ask all the employees and cooperating companies before, during and after the journey (e.g. in a BPO maturity assessment). Second, we sought to develop a layer and plotted the results from measures in relation to the major milestones in the BPO journey. However, we encountered the challenge of multiple measurement scales and the absence of a start value to compare some of the results. In addition, defining the time period of the journey was not obvious, especially with the cut-off date set to 2013 - it is difficult to know when an effect takes place. However, our detailed description of the $\mathrm{BPO}$ journey gives rich material to learn from and some effects are proven in figures and fact. Thus, our challenges in terms of measuring effects are also a lesson learned, which indicates the importance of continually measuring in the same way in order to follow up BPO initiatives.

We need greater awareness of the importance of evaluating the journey, as well as results using a stable/same scale when measuring effects in a BPO. The latter has been problematic in our study. For some effects we are able to show a baseline even some years before the journey, and for some effects we are able to show results after 2013. Owing to the ever-changing circumstances (objectives, tasks and resources), changes in performance figures cannot easily be attributed to certain causes. However, for some effects, it is easier, for example, for customer satisfaction relating to the service delivery. Further studies should relate to people's abilities in BPM roles to be able to align the top management with the operational level. Another avenue of future research is to further explore the corporate capabilities and people's abilities in relation to effectiveness and efficiency. One idea is to elaborate on a "more modeling-based communication" initiative with a "less modeling-based communication" approach. Hence, the latter might also be an element in an agile BPM to establish the relationship between effectiveness and employees' team performance. 
In conclusion, we can state that $\mathrm{KBAB}$ has had a new $\mathrm{CEO}$ since 2015 and conducted an organization review in 2016, which resulted in a new organization structure from 2017. Some BPO foundational principles are replaced with a traditional hierarchical structure and will be described as a matrix organization. Thus, access to the internal review report and a follow-up on the basis of this reorganization would be most valuable for further research.

\section{References}

Bakotić, D. (2016), "Relationship between job satisfaction and organisational performance", Economic Research-Ekonomska Istraživanja, Vol. 29 No. 1, pp. 118-130.

BeBo (2017), "19 films with KBABs employees, partners and customersviews on business performance and culture", available at: www.bebostad.se/nittonfilmer/

Beiron, J. and Olin, M. (2010), "Kreativitet, uppfinnarjockar och stollighet: En studie av företagskulturens betydelse vid Karlstads Bostads $\mathrm{AB}$ modernisering av miljonprogramområdet Orrholmen", Avdelningen för energi-, miljö- och byggteknik, Karlstads universitet (in Swedish).

Bergener, K., vom Brocke, J., Hofmann, S., Stein, A. and vom Brocke, C. (2012), "On the importance of agile communication skills in BPM education: design principles for international seminars", Knowledge Management E-Learning: International Journal, Vol. 4 No. 4, pp. 415-434.

Christiansson, M.T. and Van Looy, A. (2017), "Elements for tailoring a BPM maturity model to simplify its use", in Carmona, J., Engels, G. and Kumar, A. (Eds), Business Process Management Forum. BPM 2017. Lecture Notes in Business Information Processing, Vol. 297, Springer, Cham.

Davenport, T.H. (1993), Process Innovation - Reengineering Work through Information Technology, Harvard Business School Press, Boston, MA.

Dijkman, R., Lammers, S.V. and de Jong, A. (2016), "Properties that influence business process management maturity and its effect on organizational performance", Information Systems Frontiers, Vol. 18 No. 4, pp. 717-734.

Dumas, M., La Rosa, M., Mendling, J. and Reijers, H.A. (2013), Fundamentals of BPM, Springer, Berlin.

EFQM (2019), EFQM Excellence Model 2013, The European Foundation for Quality Management, Brussels, available at: www.efqm.org

Eicker, S., Kochbeck, J. and Schuler, P.M. (2008), "Employee competencies for business process management", in Abramowicz, W. and Fensel, D. (Eds), Proceedings of 11th International Conference on Business Information Systems, Vol. 7, LNBIP, pp. 251-262.

Fornell, C. (1992), "National customer satisfaction barometer: the Swedish experience", Journal of Marketing, Vol. 56, January, pp. 6-21.

Gazzoli, G., Hancer, M. and Kim, B.C. (2013), "Explaining why employee-customer orientation influences customers' perceptions of the service encounter", Journal of Service Management, Vol. 24 No. 4, pp. 382-400.

Goldkuhl, G. (2011), "The research practice of practice research: theorizing and situational inquiry", Systems, Signs \& Actions, Vol. 5 No. 1, pp. 7-29.

Grudin, M. (2015), "Processkartläggning som ett motiverande verktyg i verksamhetsutveckling", accessible in the archive of bachelor theses, Karlstad university, Karlstad, available at: www. diva-portal.org/smash/search.jsf?dswid=-2796 (in Swedish).

Hammer, M. (1990), "Reengineering work: don’t automate, obliterate", Harvard Business Review, July-August, pp. 104-112.

Hammer, M. (2007a), “The process audit”, Harvard Business Review, Vol. 85 No. 4, pp. 111-123.

Hammer, M. (2007b), "The 7 deadly sins of performance measurement", MIT Sloan Management Review, Vol. 48 No. 3, pp. 19-28.

Hammer, M. and Champy, J.M. (1993), Reengineering the Corporation: A Manifesto for Business Revolution, Nicholas Brealey Publishing, London. 
BPMJ

26,2

Hammer, M. and Stanton, S. (1999), "How process enterprises really work", Harvard Business Review, Vol. 77 No. 6, pp. 108-118.

Harmon, P. (2015), "The scope and evolution of business process management", in vom Brocke, J. and Rosemann, M. (Eds), Handbook on Business Process Management, Vol. 1, 2nd ed., Springer, Berlin.

Hernaus, T., Bosilj Vuksic, V. and Indihar Štemberger, M. (2016), "How to go from strategy to results? Institutionalising BPM governance within organisations", Business Process Management Journal, Vol. 22 No. 1, pp. 173-195.

KBAB (2019), Karlstads Bostads AB home page, available at: www.kbab.se/

Keen, P.G.W. (1997), The Process Edge: Creating Value Where It Counts, Harvard Business School Press, Boston, MA.

Kirchmer, M. (2017), High Performance Through Business Process Management-Strategy Execution in a Digital World, Springer, Berlin.

Kohlbacher, M. (2010), "The effects of process orientation: a literature review”, Business Process Management Journal, Vol. 16 No. 1, pp. 135-152.

Kohlbacher, M. and Gruenwald, S. (2011), "Process orientation: conceptualization and measurement", Business Process Management Journal, Vol. 17 No. 2, pp. 267-283.

Kohlbacher, M. and Reijers, H.A. (2013), "The effects of process-oriented organizational design on firm performance”, Business Process Management Journal, Vol. 19 No. 2, pp. 245-262.

Kratzer, S., Lohmann, P., Roeglinger, M., Rupprecht, L. and zur Muehlen, M. (2018), "The role of the chief process officer in organizations", Business Process Management Journal, Vol. 25, pp. 688-706.

Langley, A. (1999), "Strategies for theorizing from process data", The Academy of Management Review, Vol. 24 No. 4, pp. 691-710.

Langley, A., Smallman, C., Tsoukas, H. and van De Ven, A.H. (2013), "Process studies of change in organization and management: unveiling temporality, activity and flow", Academy of Management Journal, Vol. 56 No. 1, pp. 1-13.

Lockamy, A. III and McCormack, K. (2004), “The development of a supply chain management process maturity model using the concepts of business process orientation", Supply Chain Management: An International Journal, Vol. 9 No. 4, pp. 272-278.

McCormack, K. (2001), "Business process orientation: do you have it?”, Quality Progress, Vol. 34 No. 1, pp. 51-58.

McCormack, K. and Johnson, W.C. (2001), Business Process Orientation: Gaining the E-Business Competitive Advantage, St Lucie Press, FL.

Movahedi, B., Miri-Lavassani, K. and Kumar, U. (2016), "Operational excellence through business process orientation. An intra- and inter-organizational analysis", The TQM Journal, Vol. 28 No. 3, pp. 467-495.

Müller, O., Schmiedel, T., Gorbacheva, E. and vom Brocke, J. (2016), "Towards a typology of business process management professionals: identifying patterns of competences through latent semantic analysis", Enterprise Information Systems, Vol. 10 No. 1, pp. 50-80.

Niehaves, B., Poeppelbuss, J., Plattfaut, R. and Becker, J. (2014), "BPM capability development - a matter of contingencies", Business Process Management Journal, Vol. 20 No. 1, pp. 90-106.

Oberweis, A. (2010), "A meta-model based approach to the description of resources and skills", Proceedings of AMCIS 2010, Lima, August 12-15.

Österle, H (1995), Business in the Information Age - Heading for New Processes, Springer-Verlag, Berlin.

Palmberg, K. (2010), "Experiences of implementing process management: a multiple-case study", Business Process Management Journal, Vol. 16 No. 1, pp. 93-113.

Raschke, R.L. and Ingraham, L.R. (2010), "Business process maturity's effect on performance", Proceedings of AMCIS 2010, Lima, August 12-15. 
Rohloff, M. (2009), "Case study and maturity model for business process management implementation", in Dayal, U., Eder, J., Koehler, J. and Reijers, H.A. (Eds), BPM 2009, Vol. 5701, LNCS, pp. 128-142.

Rosemann, M. (2006), "Potential pitfalls of process modeling: part A", Business Process Management Journal, Vol. 12 No. 2, pp. 249-254.

Rosemann, M. (2010), "The service portfolio of a BPM center of excellence", in vom Brocke, J. and Rosemann, M. (Eds), Handbook on Business Process Management: Strategic Alignment, Governance, People and Culture, Springer, Berlin/Heidelberg, pp. 267-284.

Rosemann, M. (2014), "Proposals for future BPM research directions", Proceedings of Asia-Pacific Conference on Business Process Management, Springer, Cham, pp. 1-15.

Rosemann, M. and de Bruin, T. (2005), "Application of a holistic model for determining BPM maturity", BPTrends.

Rosemann, M. and vom Brocke, J. (2015), "The six core elements of business process management", in vom Brocke, J. and Rosemann, M. (Eds), Handbook on Business Process Management, Vol. 1, 2nd ed., Springer, Berlin, pp. 109-124.

Rummler, G.A. and Brache, A.P. (1995), Improving Performance - How to Manage the White Space on the Organization Chart, Jossey-Bass Publishers, San Francisco, CA.

Schmiedel, T., vom Brocke, J. and Recker, J. (2013), "Which cultural values matter to business process management? Results from a Global Delphi Study", Business Process Management Journal, Vol. 19 No. 52, pp. 292-317.

Shirani, S. (2016), "Effekter som uppstår i processorienterade organisationer", accessible in the archive of bachelor theses, Karlstad university, Karlstad, available at: www.diva-portal.org/smash/search. jsf?dswid=-2796 (in Swedish).

Skrinjar, R. and Trkman, P. (2013), "Increasing process orientation with business process management: Critical practices'”, International Journal of Information Management, Vol. 33, pp. 48-60.

Skrinjar, R., Bosilj-Vuksic, V. and Indihar-Stemberger, M. (2008), "The impact of business process orientation on financial and non-financial performance", Business Process Management Journal, Vol. 14 No. 5, pp. 738-754.

Steneskog, G. (1991), Process Management - Konsten att styra och utveckla ett företags administrativa processer, Liber, Malmö (in Swedish).

Tang, J., Pee, L.G. and Iijima, J. (2013), "Investigating the effects of business process orientation on organizational innovation performance", Information \& Management, Vol. 50 No. 8, pp. 650-660.

Tarhan, A., Turetken, O. and Reijers, H. (2015), "Do mature business processes lead to improved performance? - A review of literaturefor empirical evidence", Proceedings of ECIS 2015, Münster, May 26-29.

Thiemich, C. and Puhlmann, F. (2013), “An agile BPM project methodology”, Proceedings of BPM 2013, LNCS 8094, Springer-Verlag, Berlin, Heidelberg.

Tregear, R. (2014), "Practical process: the case for process architecture", BPTrends.

Tregear, R. (2016), "Practical process: a process by any other name”, BPTrends.

Trkman, P. (2010), "The critical success factors of business process management", International Journal of Information Management, Vol. 30 No. 2, pp. 125-134.

Van Looy, A. (2014), Business Process Maturity, SBPM, Springer, Cham.

Van Looy, A. (2017), "A quantitative study of the link between business process management and digital innovation", in Carmona, J., Engels, G. and Kumar, A. (Eds), Business Process Management Forum. BPM 2017. Lecture Notes in Business Information Processing, Vol. 297, Springer, Cham.

Van Looy, A., DeBacker, M. and Poels, G. (2014), "A conceptual framework and classification of capability areas for business process maturity”, Enterprise Information Systems, Vol. 8 No. 2, pp. 188-224.

vom Brocke, J. and Mendling, J. (2017), "Class notes: business process management cases - learning from real-world experience”, BPTrends. 
BPMJ

26,2

404 vom Brocke, J., Schmiedel, T., Recker, J.C., Trkman, P., Mertens, W. and Viaene, S. (2014), "Ten principles of good business process management", Business Process Management Journal, Vol. 20 No. 4, pp. 530-548.

vom Brocke, J., Zelt, S. and Schmiedel, T. (2016), "On the role of context in business process management", International Journal of Information Management, Vol. 36 No. 3, pp. 486-495.

Walsham, G. (2006), "Doing interpretive research”, European Journal of Information Systems, Vol. 15 No. 3, pp. 320-330.

Willaert, P. and Van den Bergh, J. (2007), "The process-oriented organisation: a holistic view developing a framework for business process orientation maturity", Proceedings of BPM 2007, LNCS 4714, Springer, Berlin, pp. 1-15.

Yin, R.K. (2014), Case Study Research: Design and Methods, SAGE, London.

Zaheer, A., Rehman, K.U. and Khan, M.A. (2010), "Development and testing of a business process orientation model to improve employee and organizational performance", African Journal of Business Management, Vol. 4 No. 2, pp. 149-161.

zur Muehlen, M. (2008), "Class notes: BPM research and education - a little knowledge is a dangerous thing", BPTrends.

\section{Corresponding author}

Marie-Therese Christiansson can be contacted at: marie-therese.christiansson@kau.se

For instructions on how to order reprints of this article, please visit our website: 